\title{
Fissile Materials Disposition Formulation Report
}

M.C. Hash, V.N. Zyryanov, J.K. Basco, D.B. Chamberlain

June 1, 1999

U.S. Department of Energy

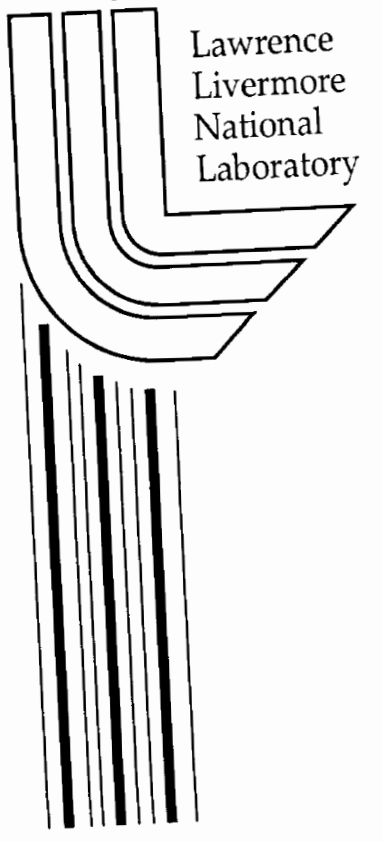




\section{DISCLAIMER}

This document was prepared as an account of work sponsored by an agency of the United States Government. Neither the United States Government nor the University of California nor any of their employees, makes any warranty, express or implied, or assumes any legal liability or responsibility for the accuracy, completeness, or usefulness of any information, apparatus, product, or process disclosed, or represents that its use would not infringe privately owned rights. Reference herein to any specific commercial product, process, or service by trade name, trademark, manufacturer, or otherwise, does not necessarily constitute or imply its endorsement, recommendation, or favoring by the United States Government or the University of California. The views and opinions of authors expressed herein do not necessarily state or reflect those of the United States Government or the University of California, and shall not be used for advertising or product endorsement purposes.

This work was performed under the auspices of the U.S. Department of Energy by the University of California, Lawrence Livermore National Laboratory under Contract No. W-7405-Eng-48.

This report has been reproduced directly from the best available copy.

Available electronically at http://www.doe.gov/bridge

Available for a processing fee to U.S. Department of Energy

and its contractors in paper from

U.S. Department of Energy

Office of Scientific and Technical Information

P.O. Box 62

Oak Ridge, TN 37831-0062

Telephone: (865) 576-8401

Facsimile: (865) 576-5728

E-mail: reports@adonis.osti.gov

Available for the sale to the public from

U.S. Department of Commerce

National Technical Information Service

5285 Port Royal Road

Springfield, VA 22161

Telephone: (800) 553-6847

Facsimile: (703) 605-6900

E-mail: orders@ntis.fedworld.gov

Online ordering: http://www.ntis.gov/ordering.htm

OR

Lawrence Livermore National Laboratory

Technical Information Department's Digital Library

http://www.llnl.gov/tid/Library.html 


\title{
Fissile Materials Disposition Formulation Report
}

\author{
By
}

M.C. Hash, V.N. Zyryanov, J.K. Basco, and D.B. Chamberlain

Argonne National Laboratory

June 1999

The submitted manuscript has been created
by the University of Chicago as Operator of
Argonne National Laboratory ("Argonne")
under Contract No. W-31-109-ENG-38 with
the U.S. Department of Energy. The U.S.
Government retains for itself, and others
acting on its behalf, a paid-up, nonexclusive,
irrevocable worddwide license in said article to
reproduce, prepare derivative works, distribute
copies to the public, and pertorm publicly and
display publicly, by or on behalf of the
Government.

Work supported by the U.S. Department of Energy, Office of Fissile Materials Disposition, under contract W-31-109-ENG-38. 



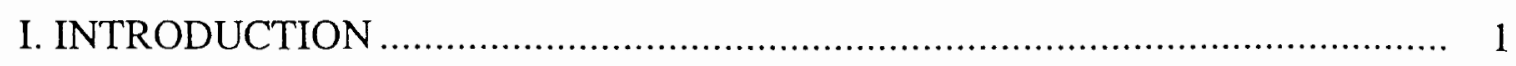

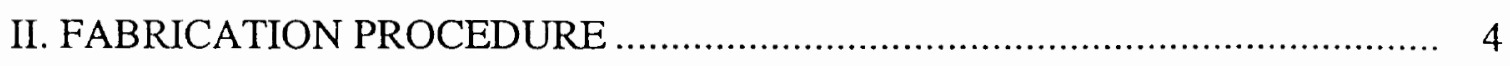

III. RESULTS AND DISCUSSION ............................................................. 5

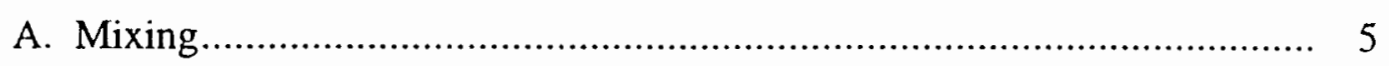

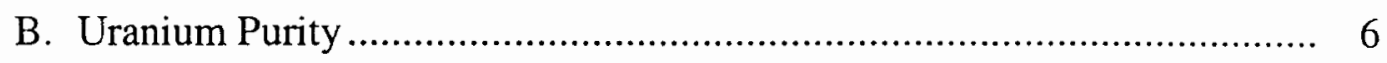

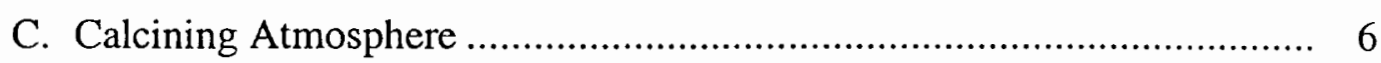

D. Sintering Atmosphere ..................................................................... 7

E. Mass Sample Fabrication and Characterization ........................................ 8

1. Reference SEM Images, XRD Patterns, and EDS Spectra ............. 12

2. Baseline Formulation - A0 .................................................... 12

3. Impurity Formulations - A9, B3-13, B3-17, B3-19 ................... 13

4. Processing and Compositional Extremes - B3-3, B3-4, B3-9, ....... 13 B3-11, and B3-21

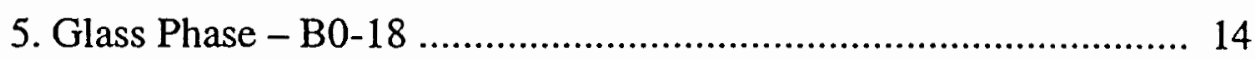

IV. FUTURE WORK

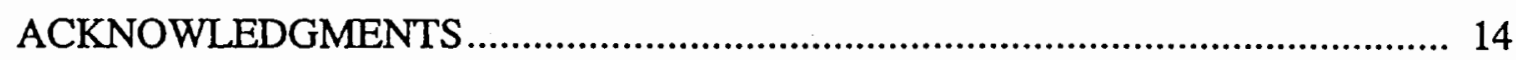

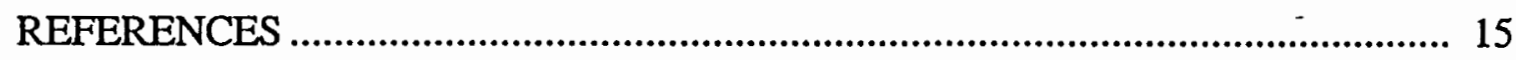

APPENDIX A. Scanning Electron Micrographs.................................................... 16

APPENDIX B. Select Powder X-ray Diffraction Patterns ........................................ 41

APPENDIX C. Example Energy Dispersive Spectra …........................................... 48

APPENDIX D. Raw Materials Used in Fabrication of Test Specimens .................... 57 


\section{LIST OF TABLES}

\section{Page}

I. Nominal Compositions of Ceramic Formulations (wt\%) ............................. 2

II. Average Bulk Densities and Estimated Porosities of Test Specimens............ 9

III. Phase Assemblages of Test Specimens from SEM/EDS/XRD Analyses ........ 11

D-I. Raw Materials Used in Fabrication of Test Specimens................................. 58 


\section{LIST OF FIGURES}

\section{$\underline{\text { Page }}$}

1. Average Bulk Densities of Baseline Specimens Containing Carbon Impurity $(A 0-1,2)$ and without this Impurity $(A 0-3,4,5)$

2. Comparison of Calcining Atmospheres for Specimens Made from Two Baseline Formulations That Use Cerium as a Chemical Surrogate for Plutonium

3. Average Bulk Densities of Specimens Sintered in Argon or Air 8

4. Average Bulk Densities of Test Specimens 10

A-1. Secondary Electron Image of A0 Specimen (300X)

A-2. Backscattered Electron Image of A0 Specimen (300X)

A-3. Backscattered Electron Image of A0 Specimen in (1000X).

A-4. Secondary Electron Image of A9 Specimen (300X)

A-5. Backscattered Electron Image of A9 Specimen (300X)

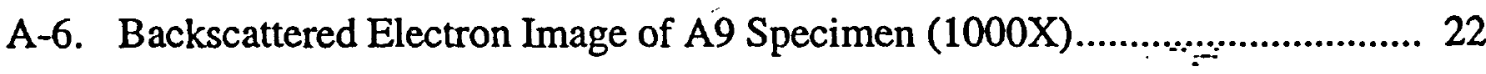

A-7. Backscattered Electron Image of B3-3 Specimen (300X)......................... 23

A-8. Backscattered Electron Image of B3-3 Specimen (1000X) 24

A-9. Backscattered Electron Image of B3-4 Specimen (300X) ......................... 25

A-10. Backscattered Electron Image of B3-4 Specimen (1000X) ....................... 26

A-11. Backscattered Electron Image of B3-9 Specimen (300X) ......................... 27

A-12. Backscattered Electron Image of B3-9 Specimen (1000X). 


\section{LIST OF FIGURES (Contd.)}

A-13. Backscattered Electron Image of B3-11 Specimen (300X) ......................... 29

A-14. Backscattered Electron Image of B3-11 Specimen (1000X) ........................ 30

A-15. Backscattered Electron Image of B3-13 Specimen (300X) .......................... 31

A-16. Backscattered Electron Image of B3-13 Specimen (1000X) ......................... 32

A-17. Backscattered Electron Image of B3-17 Specimen (300X) .......................... 33

A-18. Backscattered Electron Image of B3-17 Specimen (1000X) ........................ 34

A-19. Backscattered Electron Image of B3-19 Specimen (300X) .......................... 35

A-20. Backscattered Electron Image of B3-19 Specimen (1000X)......................... 36

A-21. Backscattered Electron Image of B3-21 Specimen (300X) ........................... 37

A-22. Backscattered Electron Image of B3-21 Specimen (1000X) ......................... 38

A-23. Backscattered Electron Image of B0-18 Specimen after Slow Cooling

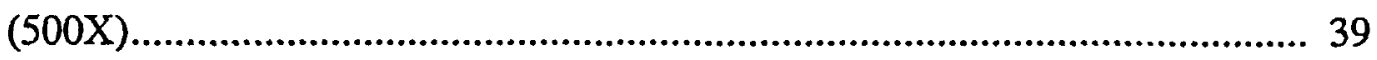

A-24. Backscattered Electron Image of B0-18 Specimen after Slow Cooling

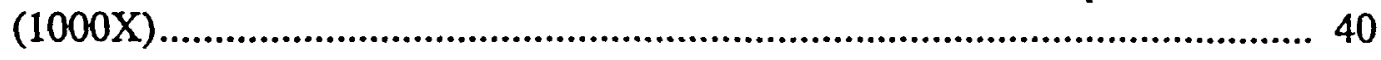

B-1. Powder X-ray Diffraction Pattern of A0 Sample Sintered in Argon ............... 42

B-2. Powder X-ray Diffraction Pattern of B3-4 Sample Sintered in Argon ............ 43

B-3. Powder X-ray Diffraction Pattern of B3-13 Sample Sintered in Argon ......... 44

B-4. Powder X-ray Diffraction Pattern of B3-13 Sample Sintered in Air ............... 45

B-5. Powder X-ray Diffraction Pattern of B3-17 Sample Sintered in Argon .......... 46 


\section{LIST OF FIGURES (Contd.)}

B-6. Powder X-ray Diffraction Pattern of B3-17 Sample Sintered in Air.

C-1. Typical Energy Dispersive Spectra of Pyrochlore Phase 49

C-2. Typical Energy Dispersive Spectra of Brannerite Phase 50

C.3. Typical Energy Dispersive Spectra of Zirconolite Phase 51

C-4. Typical Energy Dispersive Spectra of Rutile Phase. 52

C-5. Typical Energy Dispersive Spectra of Perovskite Phase. 53

C-6. Typical Energy Dispersive Spectra of Silicate Phase 54

C-7. Typical Energy Dispersive Spectra of Phosphate Phase 55

C-8. Typical Energy Dispersive Spectra of Actinide Oxide Phase 56 

Fissile Materials Disposition

Formulation Report

Argonne National Laboratory

June 1999

M.C. Hash, V.N. Zyryanov, J.K. Basco, and D.B. Chamberlain

\section{INTRODUCTION}

The Department of Energy (DOE) has chosen a titanate-based ceramic as the preferred form for the immobilization of surplus plutonium [COCHRAN]. The baseline formulation being developed includes a pyrochlore matrix, $(\mathrm{Ca}, \mathrm{Gd}, \mathrm{Pu}, \mathrm{U}, \mathrm{Hf})_{2} \mathrm{Ti}_{2} \mathrm{O}_{7}$, the primary site for plutonium and uranium, and several minor phases such as brannerite, $(\mathrm{Pu}, \mathrm{U}) \mathrm{Ti}_{2} \mathrm{O}_{6}$, and rutile, (TiHf) $\mathrm{O}_{2}$. This baseline and ten other formulations were prepared to provide test specimens for characterization and corrosion testing. The purpose of this report is to document the fabrication and characterization of these ceramics.

The fabrication procedure initially employed to produce specimens was provided by Lawrence Livermore National Laboratory (LLNL). During the preparation of the baseline ceramic, several aspects related to LLNL's procedure were evaluated. This report will discuss how these techniques were refined to reproducibly provide ceramics appropriate for corrosion testing.

The baseline formulation represents a titanate ceramic for which the plutonium feed stream would be free of any impurity elements. The other formulations were designed to provide information about potential phase formation due to variations in precursors, specifically the waste streams in which the surplus plutonium is contained. Nominal compositions representing the 11 formulations investigated are shown in Table I. 

Table 1. Nominal Compositions of Ceramic Formulations (wt\%)

\begin{tabular}{|c|c|c|c|c|c|c|c|c|c|c|c|}
\hline Compound & A0 & A9 & B3-3 & B3-4 & B3-9 & B3-11 & B3-13 & B3-17 & B3-19 & B3-21 & B0-18 \\
\hline $\mathrm{CaO}$ & 9.95 & 9.45 & 9.24 & 5.84 & 12.07 & 11.61 & 8.30 & 7.92 & 3.19 & 15.91 & 13.11 \\
\hline $\mathrm{TiO}_{2}$ & 35.87 & 34.07 & 33.85 & 36.99 & 36.19 & 32.48 & 33.80 & 32.46 & 28.73 & 33.99 & 8.10 \\
\hline $\mathrm{HfO}_{2}$ & 10.65 & 10.12 & 24.21 & 9.92 & 10.88 & 9.69 & 10.27 & 9.64 & 8.51 & 10.22 & 1.37 \\
\hline $\mathrm{Gd}_{2} \mathrm{O}_{3}$ & 7.95 & 7.55 & 6.60 & 6.32 & 7.66 & 8.50 & 7.52 & 7.20 & 6.36 & 7.20 & 1.06 \\
\hline $\mathrm{UO}_{2}$ & 23.69 & 22.50 & 15.40 & 27.96 & 20.83 & 21.35 & 22.31 & 21.44 & 18.78 & 19.57 & 2.68 \\
\hline $\mathrm{PuO}_{2}$ & 11.89 & 11.29 & 9.57 & 12.98 & 12.36 & 13.03 & 11.20 & 10.76 & 9.43 & 13.11 & 2.44 \\
\hline $\mathrm{CeO}_{2}$ & - & - & - & - & - & - & 0.18 & 0.14 & 0.23 & - & - \\
\hline $\mathrm{Al}_{2} \mathrm{O}_{3}$ & - & 0.50 & 1.13 & - & - & - & 0.72 & 2.48 & 1.31 & - & 19.54 \\
\hline $\mathrm{B}_{2} \mathrm{O}_{3}$ & - & 0.17 & - & - & - & - & 0.10 & 0.18 & 0.22 & - & 5.43 \\
\hline $\mathrm{BaO}$ & - & - & - & - & - & - & 0.14 & 0.12 & 0.44 & - & - \\
\hline $\mathrm{CaCl}_{2}$ & - & 0.66 & - & - & - & - & 0.67 & 1.11 & 1.69 & - & - \\
\hline $\mathrm{Cr}_{2} \mathrm{O}_{3}$ & - & 0.08 & - & - & - & - & 0.05 & 0.15 & 0.17 & - & - \\
\hline $\mathrm{Cu}_{2} \mathrm{O}$ & - & - & - & - & - & - & 0.12 & - & 0.26 & - & - \\
\hline $\mathrm{CaF}_{2}$ & - & 0.44 & - & - & - & - & 1.03 & 0.73 & 5.36 & - & - \\
\hline $\mathrm{FeO}$ & - & 0.07 & - & - & - & - & 0.19 & 0.51 & 0.64 & - & 0.20 \\
\hline $\mathrm{Ga}_{2} \mathrm{O}_{3}$ & - & 0.57 & - & - & - & - & 0.39 & - & 1.12 & - & 2.56 \\
\hline $\mathrm{K}_{2} \mathrm{O}$ & - & 0.32 & - & - & - & - & 0.23 & 0.96 & 0.83 & - & 0.65 \\
\hline $\mathrm{La}_{2} \mathrm{O}_{3}$ & - & - & - & - & - & - & 0.02 & 0.02 & 0.18 & - & - \\
\hline $\mathrm{MgO}$ & - & 0.44 & - & - & - & - & 0.43 & $0 . \ddot{9}^{-=}$ & 3.25 & - & 1.31 \\
\hline $\mathrm{MnO}$ & - & - & - & - & - & - & - & - & 0.01 & - & - \\
\hline $\mathrm{MoO}_{2}$ & - & 0.28 & - & - & - & - & 0.16 & 0.18 & 0.28 & - & 0.44 \\
\hline $\mathrm{Na}_{2} \mathrm{O}$ & - & 0.14 & - & - & - & - & 0.23 & 0.39 & 0.28 & - & 3.35 \\
\hline $\mathrm{NiO}$ & - & 0.13 & - & - & - & - & 0.09 & 0.29 & 0.30 & - & - \\
\hline $\mathrm{Nd}_{2} \mathrm{O}_{3}$ & $\cdot$ & - & - & - & - & - & 0.29 & - & 1.28 & - & - \\
\hline $\mathrm{P}_{2} \mathrm{O}_{5}$ & - & - & - & - & - & 3.34 & 0.01 & - & 0.14 & - & 2.68 \\
\hline $\mathrm{PbO}$ & - & - & - & - & $\cdot$ & - & 0.52 & - & 1.00 & - & - \\
\hline $\mathrm{SiO}_{2}$ & - & 0.46 & - & - & - & - & 0.88 & 2.14 & 4.92 & - & 35.08 \\
\hline
\end{tabular}


Table 1. Nominal Compositions of Ceramic Formulations (wt $\%$ ) - continued

\begin{tabular}{l|ccccccccccc} 
Compound & $\mathrm{A} 0$ & $\mathrm{~A} 9$ & $\mathrm{~B} 3-3$ & $\mathrm{~B} 3-4$ & $\mathrm{~B} 3-9$ & $\mathrm{~B} 3-11$ & $\mathrm{~B} 3-13$ & $\mathrm{~B} 3-17$ & $\mathrm{~B} 3-19$ & $\mathrm{~B} 3-21$ & $\mathrm{~B} 0-18$ \\
\hline $\mathrm{SnO}_{2}$ & - & - & - & - & - & - & 0.01 & - & 0.03 & - & - \\
$\mathrm{Ta}_{2} \mathrm{O}_{5}$ & - & 0.19 & - & - & - & - & 0.08 & 0.22 & 0.65 & - & - \\
$\mathrm{WO}_{2}$ & - & 0.49 & - & - & - & - & 0.02 & - & 0.22 & - & - \\
$\mathrm{ZnO}$ & - & 0.07 & - & - & - & - & 0.06 & - & 0.24 & - & - \\
$\mathrm{ZrO}_{2}$ & - & - & - & - & - & - & - & - & 0.002 & - & -
\end{tabular}


There are several reasons for fabricating this series of ceramics. First, it is important to understand what phases are generated as the mix of impurities changes. As the phase assemblage changes, the corrosion behavior of these ceramics may change. Of paramount concern is the potential change in the plutonium release rate. These formulations were therefore designed to yield phases, or as in the case of B0-18, a single-phase material, that may contain plutonium and subsequently may impact the corrosion behavior of this critical element. Second, information is needed on how changes in precursor chemistry impact densification. Uniformly shaped and high bulk density products are desired in production of these ceramics. Impurities are expected to affect these characteristics via minor phase formations, not necessarily plutonium-bearing, or volatilizations that alter the kinetics and reactions involved in densification.

Several techniques were used to analyze the resulting products. Bulk density of specimens, as determined geometrically, was used to gauge the relative levels of densification achieved during reactive sintering. Therefore, all specimens produced were measured and weighed.

Scanning electron microscopy (SEM) in conjunction with energy dispersive spectroscopy (EDS) was employed to identify the phase assemblage and distribution in cross sections of sintered pellets. Image analysis was used to quantify the volume percentages occupied by the various phases. The SEM/EDS data were supplemented by powder X-ray diffraction (XRD) data to confirm the presence and structure of major crystalline phases.

Samples of each ceramic have been produced for dissolution and analysis with inductively coupled plasma/mass spectroscopy (ICP-MS) techniques to determine their elemental content. Also, He-pycnometry will be used to determine the true volumes of the resulting monoliths representing the various formulations. These data are currently being collected and will be documented in future reports.

\section{Fabrication Procedure}

Test specimens were made from powders having the formulations shown in Table I. The raw materials used are described in Appendix D. These raw materials were mixed by the following standardized wet-milling technique. Powders were weighed in proper proportions and added to high-density polyethylene bottles along with an appropriate amount of deionized water and yttria-toughened zirconia grinding media ( $1 / 4$ " diameter balls). . The powderwater slurries were kept relatively dilute. For instance, the ratio of water to total powder was kept at a minimum of $\sim 2: 1$ by weight; commonly, a 4:1 ratio was used. These slurries were rolled for $\sim 16$ hours to ensure intimate mixing and size reduction of any coarse particles.

The well-mixed slurries were poured into a Pyrex dish and then heated to dryness (typically at $110^{\circ} \mathrm{C}$ for 16 hours). Once dry, the resulting powder cakes 
were pushed through a \#20 mesh sieve to form granules suitable for continued processing.

The dried granules were placed in a platinum vessel and were calcined at $750^{\circ} \mathrm{C}$ for 1 hour in either air or flowing argon. The calcined granules were then uniaxially pressed at $\sim 69 \mathrm{MPa}(10,000 \mathrm{psi})$ to form green, or unfired, pellets. A Carver Press, Model \#3912, and a 1/2" or a 1-1/8" diameter die set were used to prepare all of these samples. Green densities were determined geometrically. The pellets were then placed on platinum setters coated with granules of similar or identical composition to avoid sticking. Finally, the pressed pellets were reactively sintered at $1350^{\circ} \mathrm{C}$ for 4 hours; the heating and cooling rates were $2.5^{\circ} \mathrm{C} / \mathrm{min}$. A bottom-loading Deltec furnace, Model \#DT-31-RS-B, was used for the sintering process. Most specimens were sintered under an argon purge $(1 \mathrm{~L} / \mathrm{min})$. Some pellets were sintered in stagnant air for comparison.

\section{RESULTS AND DISCUSSION}

A number of baseline specimens were initially produced to test various processing parameters. The processing refinements described below were then employed in making representative specimens of all formulations. These final specimens are being fully characterized to provide data necessary for understanding results from subsequent corrosion tests.

Green densities of pressed pellets showed little variation. All were $40 \%$ of their final theoretical density. The granules created after drying, by pushing the dried cakes through a \#20 mesh sieve, provided an appropriate level of flow for loading into pressing dies. Since these granules were made up of agglomerated fine powders, it was necessary to limit applied uniaxial loads to $\sim 69 \mathrm{MPa}$ and pellet height to diameter ratios to $\sim 0.25$ to avoid pressing flaws such as lateral cracking.

\section{A. Mixing}

Raw mixing proved to be a critical processing step. Insufficient mixing and milling resulted in relatively less-reactive powders. Since the desired phases are formed during densification by reactive sintering mechanisms, it is extremely important that the materials be in intimate contact [KINGERY]. As mentioned previously, we adopted a 16-hour milling cycle time to ensure sufficient mixing and particle size reduction. Powders mixed less aggressively, say, for only one hour, yielded poorly reacted products; this condition was evident by limited densification. Analysis by SEM confirmed that the precursors had not reacted sufficiently. For instance, baseline specimens prepared from powders that were ball milled only one hour had an average bulk density of $4.9 \mathrm{~g} / \mathrm{cm}^{3}$, while those milled for 16 hours consistently yielded ceramics with average bulk densities greater than $5.2 \mathrm{~g} / \mathrm{cm}^{3}$ (sample standard deviation $<0.1 \mathrm{~g} / \mathrm{cm}^{3}$ ). Figure 1 illustrates this difference. The A0-1 baseline specimens were made from powders milled for only one hour. All other specimens represented in Figure 1 were made from powders milled for 16 hours. 
B. Uranium Purity

Uranium purity also proved critical. The initial two batches of baseline ceramic, A0-1 and A0-2, were prepared using $\mathrm{UO}_{2}$ that contained approximately $0.7 \mathrm{wt} \%$ carbon contamination. The final densities of these two batches were 4.91 and $5.21 \mathrm{~g} / \mathrm{cm}^{3}$ (both $\pm 0.10 \mathrm{~g} / \mathrm{cm}^{3}$ ). Three other batches of baseline material were prepared, labeled A0-3, 4, and 5, that did not contain any detectable carbon in the $\mathrm{UO}_{2}$. The densities of specimens made from these powder batches averaged 5.56, $5.61,5.48 \mathrm{~g} / \mathrm{cm}^{3}$ (all $\left.\pm 0.01 \mathrm{~g} / \mathrm{cm}^{3}\right)$. As illustrated in Figure 1, the purer $\mathrm{UO}_{2}$ stock consistently attained denser final products.

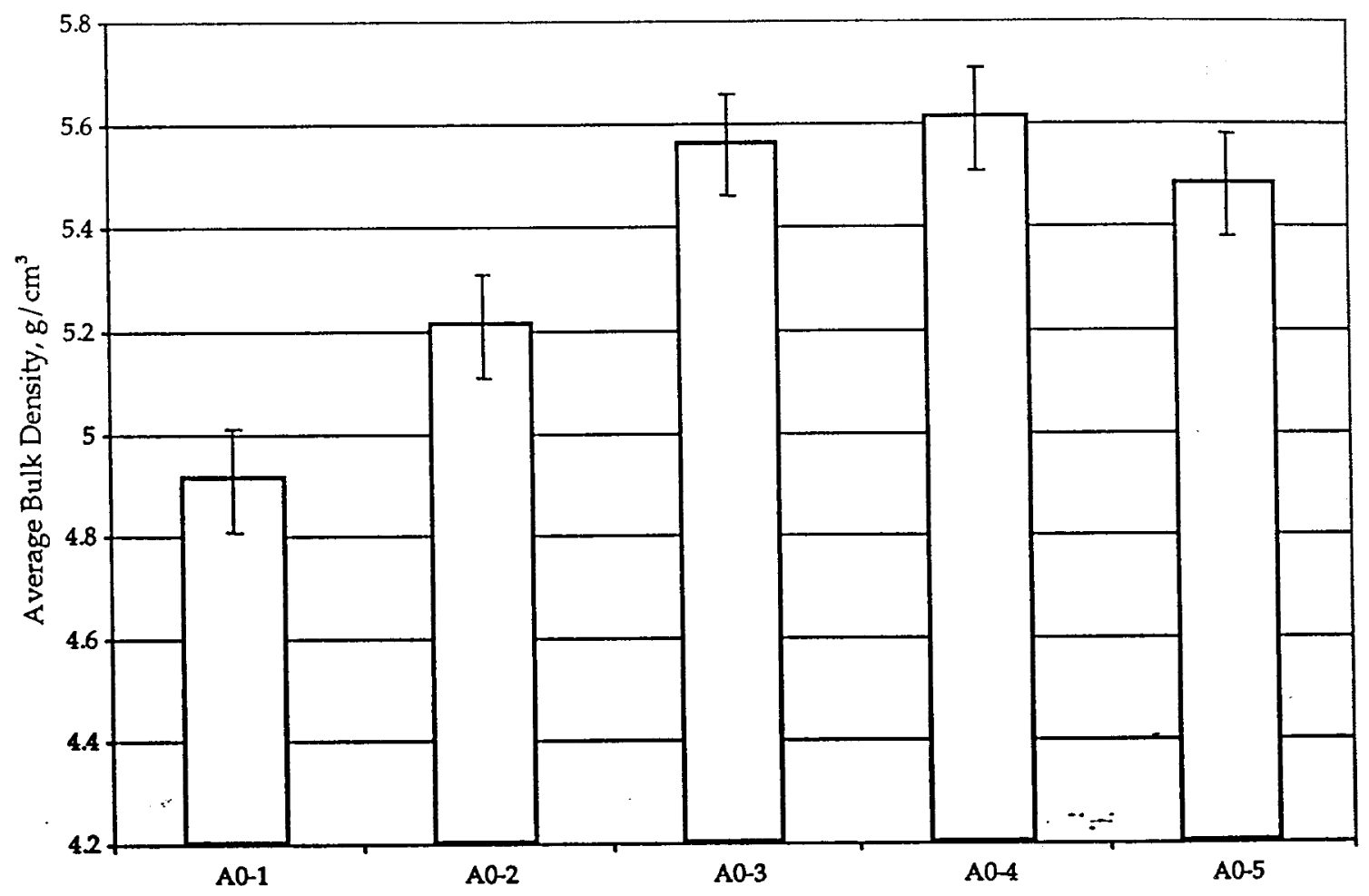

Figure 1. Average Bulk Densities of Baseline Specimens Containing Carbon Impurity $(\mathrm{A} 0-1,2)$ and without this Impurity $(\mathrm{A} 0-3,4,5)$

\section{Calcination Atmosphere}

Processing techniques initially recommended by LLNL called for powders to be calcined in an inert atmosphere. It was later thought that calcining the powders in an oxidizing atmosphere, such as air, may actually improve the reactivity of the relatively refractory uranium oxide by changing its oxidation state from +4 to +5 . To test this hypothesis specimens were made from two different powders that used cerium as a chemical surrogate for plutonium. The calcined powders 
differed in that two were calcined in air and the others under flowing argon ( $99.999 \%$ purity level). Resulting specimens showed no discernable difference in degree of densification as illustrated in Figure 2. This result supports using air in the calcination of all subsequent materials. Although air calcination did not seem to improve densification of these baseline samples, it may be of great benefit for efficient removal of potential carbon contaminants in non-baseline formulations.

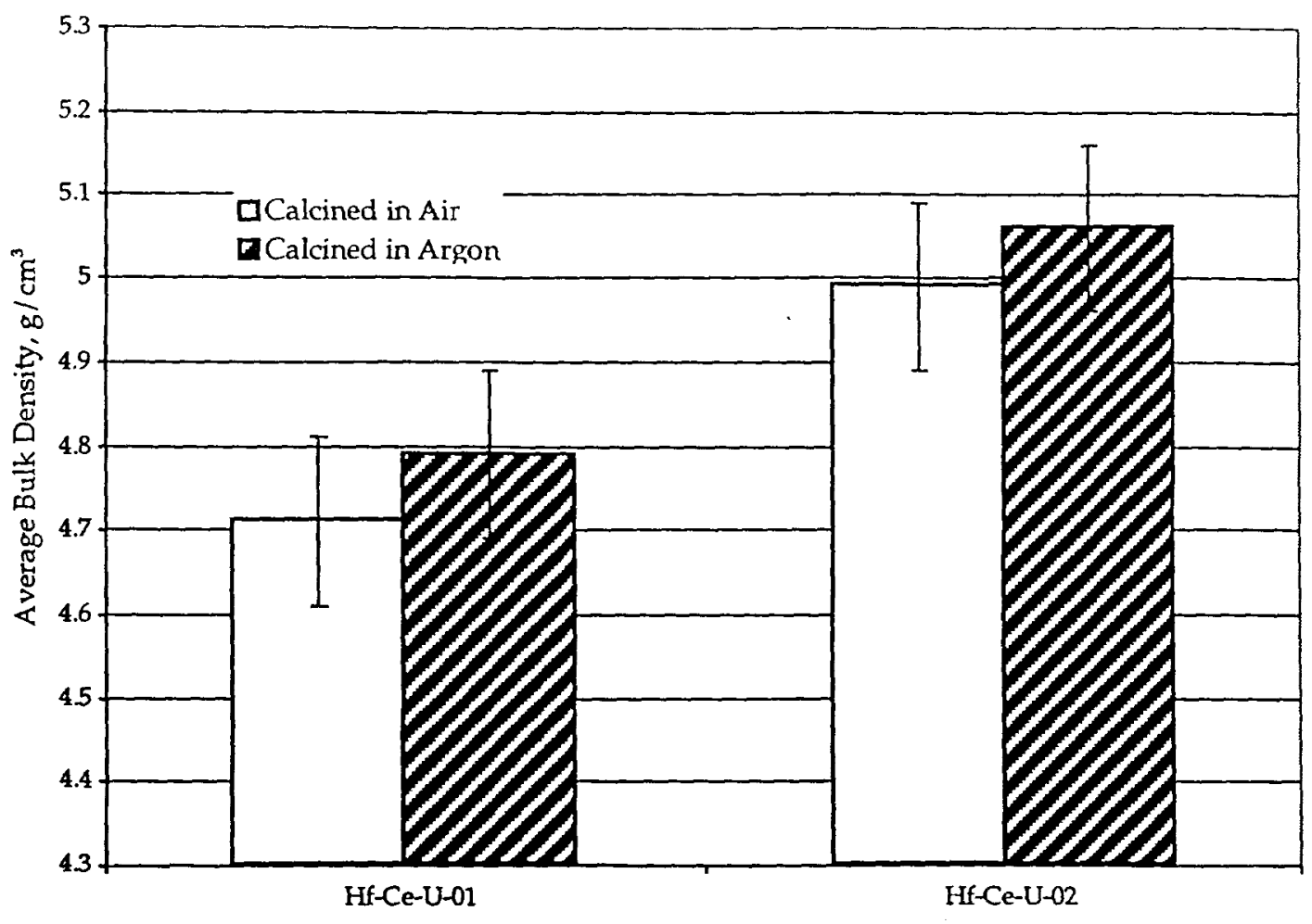

Figure 2. Comparison of Calcination Atmospheres for Specimens Made from Two Baseline Formulations That Use Cerium as a Chemical Surrogate for Plutonium

\section{Sintering Atmosphere}

Sintering in air was also investigated. As shown in Figure 3, side-by-side experiments showed that regardless of overall composition sintering in stagnant air yielded comparable products in terms of bulk density to those made under an argon purge. Phase assemblage of the like-specimens represented in Figure 3 also appears unchanged in XRD analysis (see Figures B-3, 4, 5, and 6). This is encouraging for scaling up the processing techniques. Being able to process in air greatly simplifies equipment design and control. 


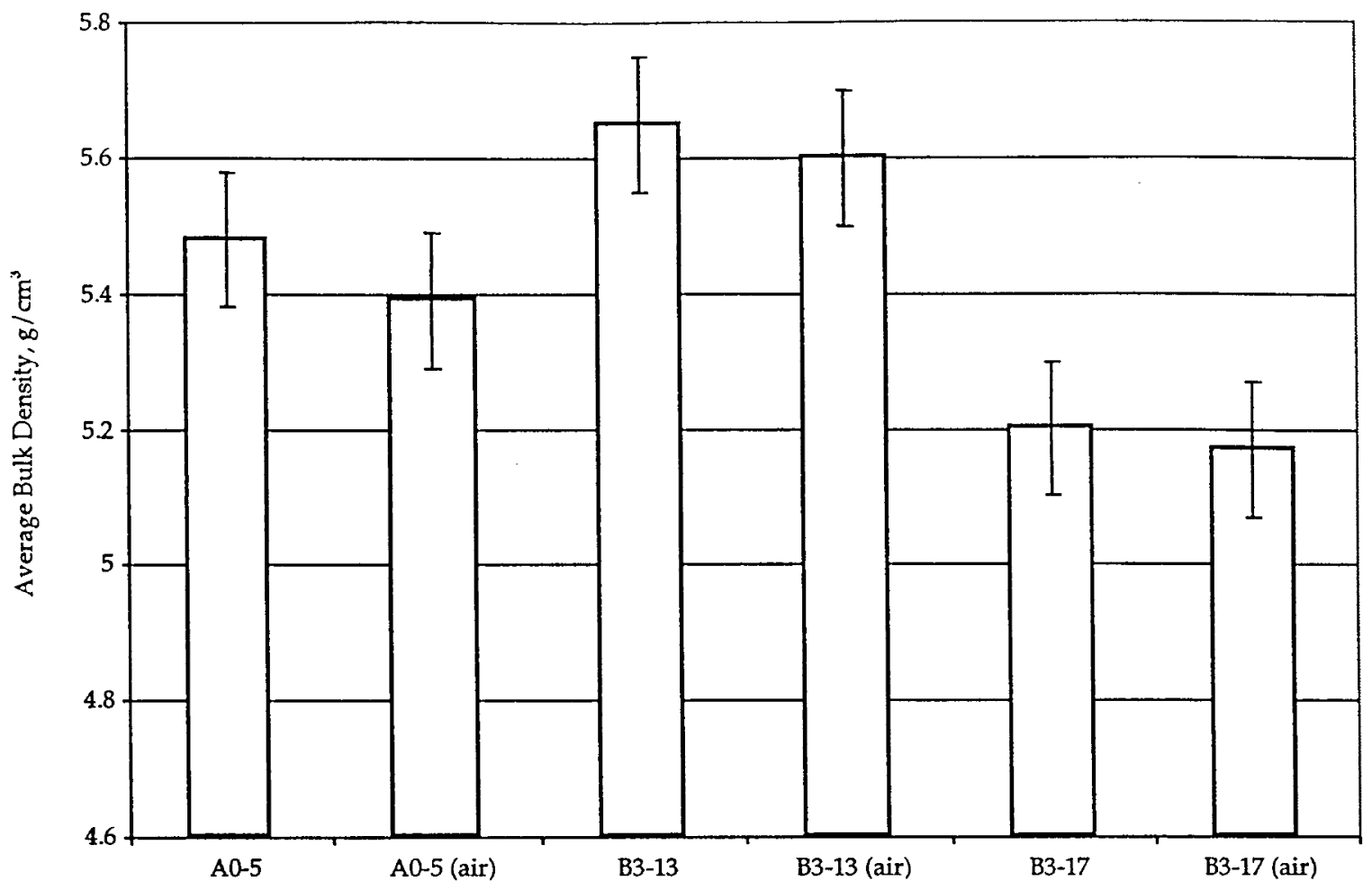

Figure 3. Average Bulk Densities of Specimens Sintered in Argon or Air

E. Mass Sample Fabrication and Characterization

By use of refined processing techniques including a 16-hour raw milling cycle, calcination in air at $750^{\circ} \mathrm{C}$ for 1 hour, and sintering in argon-at $1350^{\circ} \mathrm{C}$ for 4 hours, final specimens of each formulation were prepared. Monolithic corrosion test specimens were prepared directly from $\sim 0.8 \mathrm{~g}$ pellets to eliminate the need for cutting larger pieces down to size. This greatly reduced our overall waste volume. These shorter pellets were also easier to press, as discussed above, avoiding forming flaws that can occur when uniaxially cold pressing fine powders.

Final bulk densities were determined using the geometric volume and mass of each pellet. The average bulk density and sample standard deviation for each composition are reported in Table 2 and plotted in Figure 4. Also included in Table 2 is an estimate of the porosity of the samples based upon image analysis of SEM photomicrographs. For SEM analysis, full cross-sectional samples of each ceramic composition were mounted. Phases were identified initially by EDS and, when possible, confirmed by XRD. Both secondary and backscattered 
electron images were used to quantify volume percentages occupied by the various phases. Image analysis was done using a 150-point grid; randomly sampling each image 4 times for each phase identified. The results are shown in Table 3.

Table 2. Average Bulk Densities and Estimated Porosities of Test Specimens

\begin{tabular}{|c|c|c|}
\hline Formulation & $\begin{array}{l}\text { Average Bulk Density } \\
\left(\mathrm{g} / \mathrm{cm}^{3} \text {, geometric }\right)\end{array}$ & $\begin{array}{l}\text { Estimated Porosity } \\
\text { (vol\%, image analysis) }\end{array}$ \\
\hline A0 & $\begin{array}{c}5.48 \\
(n=49, s=0.07)\end{array}$ & 2 \\
\hline A9 & $\begin{array}{c}5.56 \\
(n=6, s=0.19)\end{array}$ & 3 \\
\hline B3-3 & $\begin{array}{c}5.29 \\
(\mathrm{n}=4, \mathrm{~s}=0.06)\end{array}$ & 2 \\
\hline B3-4 & $\begin{array}{c}5.30 \\
(\mathrm{n}=4, \mathrm{~s}=0.10)\end{array}$ & 5 \\
\hline B3-9 & $\begin{array}{c}5.43 \\
(n=4, s=0.04)\end{array}$ & 5 \\
\hline B3-11 & $\begin{array}{c}5.39 \\
(n=4, s=0.03)\end{array}$ & 4 \\
\hline B3-13 & $\begin{array}{c}5.65 \\
(n=4, s=0.08)\end{array}$ & 7 \\
\hline B3-17 & $\begin{array}{c}5.20 \\
(n=4, s=0.07)\end{array}$ & $10 .=$ \\
\hline B3-19 & $\begin{array}{c}4.42 \\
(n=4, s=0.07)\end{array}$ & 20 \\
\hline B3-21 & $\begin{array}{c}5.14 \\
(n=4, s=0.06)\end{array}$ & 5 \\
\hline
\end{tabular}

all bulk densities were determined from the geometrically determined volume, where $n$ is equal to the number of samples and $s$ is the sample standard deviation.

bstimated porosity levels \pm 2 vol\%. 


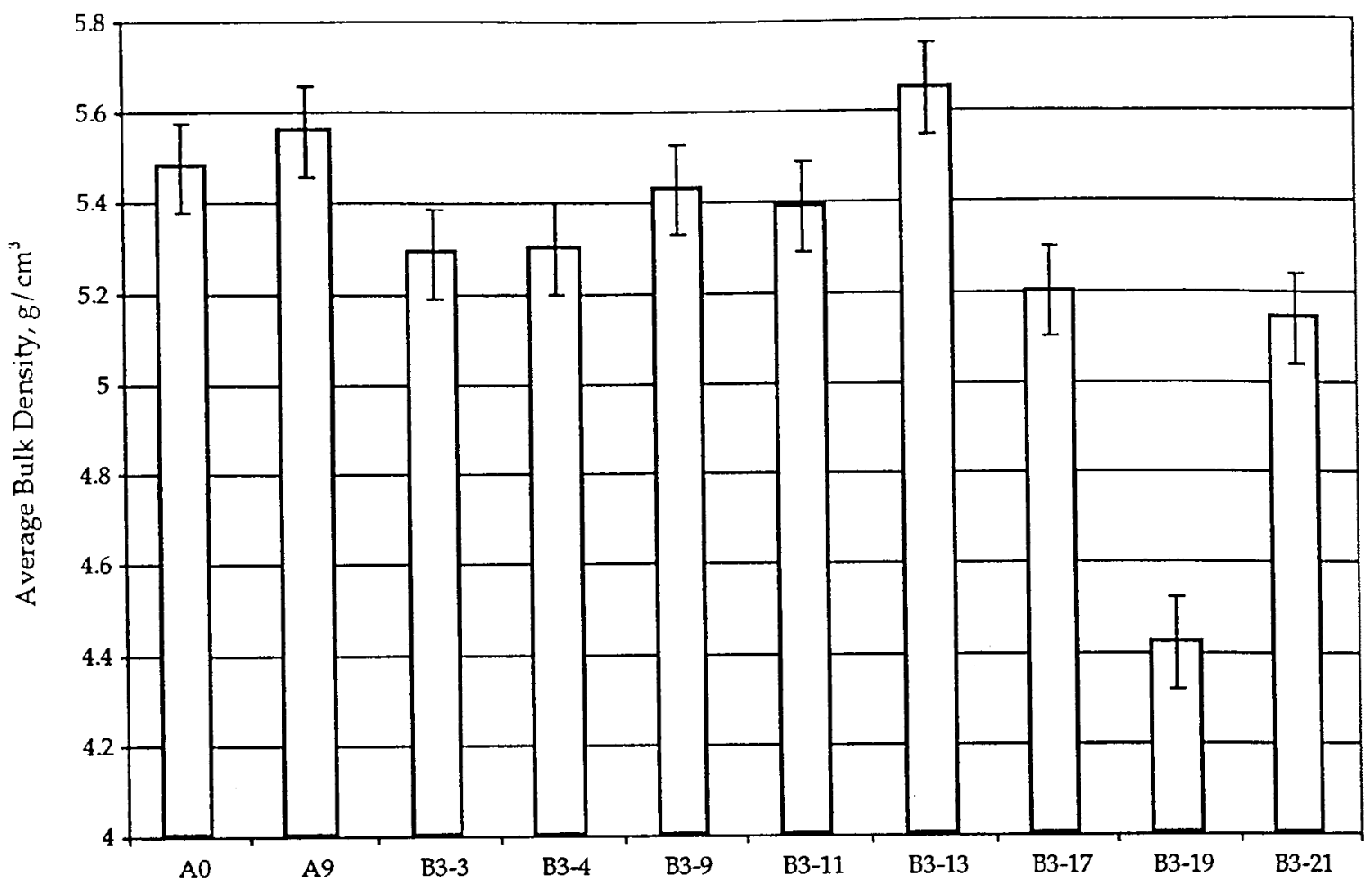

Figure 4. Average Bulk Densities of Test Specimens 
Table 3. Phase Assemblages of Test Specimens from SEM/EDS/XRD Analyses

\begin{tabular}{|c|c|c|c|c|c|c|c|c|}
\hline \multirow{2}{*}{ Formulation } & \multicolumn{5}{|c|}{ Phases Present $t^{\mathbf{a}}$ and Estimated } & \multicolumn{3}{|c|}{ Volume Percent Solids } \\
\hline & Py & $\mathrm{Br}$ & $\mathrm{Zr}$ & $\mathrm{Ru}$ & $A c$ & $\operatorname{Pr}$ & $\mathrm{Si}$ & \\
\hline A0 & 78 & 18 & $-\mathrm{b}$ & 3 & $<1$ & - & - & - \\
\hline A9 & 66 & 18 & 7 & 7 & $<1$ & - & 1 & - \\
\hline B3-3 & 41 & 8 & 38 & 12 & $<1$ & - & - & - \\
\hline B3-4 & 72 & 16 & 5 & 6 & $<1$ & - & - & - \\
\hline B3-9 & 89 & - & 4 & 7 & - & - & - & - \\
\hline B3-11 & 84 & 2 & - & 5 & $<1$ & - & - & 8 \\
\hline B3-13 & 72 & 9 & 3 & 13 & $<1$ & - & 2 & - \\
\hline B3-17 & 54 & 4 & 30 & 8 & $<1$ & - & 3 & - \\
\hline B3-19 & 12 & - & 64 & - & - & - & 24 & - \\
\hline B3-21 & 91 & - & 3 & - & - & 6 & - & - \\
\hline
\end{tabular}

a Where $\mathrm{Py}=$ pyrochlore, $\mathrm{Br}=$ brannerite, $\mathrm{Zr}=$ zirconolite, $\mathrm{Ru}=$ rutile, $\mathrm{Ac}=$ actinide oxide, $\mathrm{Pr}=$ perovskite, $\mathrm{Si}=$ silicate, and $\mathrm{Ph}=$ phosphate. All values \pm 2 vol $\%$.

b A "-" indicates this phase was not detected by SEM/EDS techniques.

Note: The phase distribution data shown in Table 3 represents an estimation of various phases that have been identified by SEM/EDS techniques only. For the major phases, their presence was verified by XRD data. These data do not preclude the presence of phases not identified by these methods. For instance, TEM analyses has identified the presence of zirconolite in the baseline formulation [BAKEL]. Our data for the baseline formulation A0 shown in Table 3 does not include zirconolite since it was not observed during SEM/EDS analysis. 
1. Reference SEM Images, XRD Patterns, and EDS Spectra

Backscattered electron and secondary electron images were taken at standard magnifications of 100,300,1000, and 3000X. Photomicrographs of each composition, sintered in argon, taken at magnifications of 300 and 1000X, are included in Appendix A. Both secondary and backscattered images at 300X were most useful for quantification of porosity and illustration of its distribution. Backscattered images at 1000X were used for quantification of solid phases. The SEM used was a Hitachi S-3000 with a solid-state backscattered electron detector and a Vantage $X$-ray microanalysis system.

Two typical XRD patterns representing bulk powder samples from the $\mathrm{A} 0$ and B3-4 formulations are included as Appendix B. Also included in this appendix are XRD patterns representing B3-13 and B3-17 specimens that were sintered in argon or air. All of these randomly collected powder samples were contained in glass capillaries, which accounts for the amorphous background, or hump, at lower $\mathrm{d}$-spacings. A Debye-Scherrer $\mathrm{X}$-ray diffraction analyzer (tabletop unit PW1729) was used with a 4 hour exposure time. We continue to collect XRD patterns for all of the ceramics produced in this study. These data will be reported in future reports.

Appendix C contains example EDS spectra of the various phases identified in the analyses of these ceramics.

\section{Baseline Formulation-A0}

As discussed previously, production of high density baseline specimens became routine after changing to a 16-hour milling cycle and using $\mathrm{UO}_{2}$ free of carbon contamination. These specimens contain brannerite, rutile, and pores evenly distributed within a pyrochlore matrix. The minor, actinide oxide phase seen in these ceramics and in other compositions listed in Table 3 is believed to be a reaction product rather than non-reacted raw material. There are two reasons for this conclusion;

- the phase appears to be a mixture of plutonium and uranium oxide (see Figure C-8; EDS spectra of actinide oxide phase), and

- the presence of this phase seems to be dependent on the starting material composition and not on powder processing techniques, since all of the specimens described in Table 3 were made the same way.

This actinide oxide phase is always located within brannerite grains. There was no discernible difference in phase assemblage or distribution throughout the cross-section.

SEM photomicrographs representing these specimens are shown in Appendix A, Figures A-1, A-2, and A-3. 


\section{Impurity Formulations - A9, B3-13, B3-17, and B3-19}

These four compositions, A9, B3-13, B3-17, and B3-19 were prepared to evaluate how different levels of impurities impact the sample morphology. As in the baseline specimens, all of the secondary phases (brannerite, zirconolite, rutile, silicate, and pores) are evenly distributed throughout the matrix. The one exception, again, is the actinide oxide phase, which only appears within brannerite grains.

All specimens made from these formulations contained notable amounts of a silicate phase. This phase is believed to be amorphous. Similar phases have been examined with transmission electron microscopy in which the vitreous state of the phase was confirmed [BAKEL].

Based upon these samples, only extremely high levels of impurity elements affect the bulk density. Sample B3-19 contains $27 \mathrm{wt} \%$ impurities, which is considered non-realistic in terms of expected feed material to the immobilization process. This sample does provide verification of the trend observed between B3-13 and B3-17 specimens, which contained 8 and $13 \mathrm{wt} \%$ impurity compounds, respectively (see Tables 2 and 3 and Figure 4). The bulk density of B3-19 is much lower than that of either B3-13 or B3-17. The increasing level of impurity elements also shifted the phase assemblage towards higher quantities of the zirconolite and silicate phases. The B3-19 micrographs (Figures A-19 and 20) show the extreme situation where large zirconolite grains are growing within a silicate phase; brannerite and actinide oxide phases are not present, and the pyrochlore content has been greatly reduced (see Table 3 ).

SEM micrographs of these specimens are shown in Appendix A: Figures A-4, A5, and A-6 (A9); A-15 and A-16 (B3-13); A-17 and A-18 (B3-17); A-19 and A-20 (B3-19).

\section{Processing and Compositional Extremes - B3-3, B3-4, B3-9, B3̈=11, and B3-21}

These specimens were produced to study the effects of various plutoniumbearing secondary phases on consolidation and corrosion behavior. All specimens prepared from these formulations densified uniformly to $>95 \%$ of their theoretical density (as defined by the estimated porosity values given in Table 2). As seen in Table 3, all of these formulations resulted in the formation or increase in the percentage of another plutonium-bearing phase at the expense of pyrochlore. These phases include zirconolite, brannerite, perovskite, and a phosphate phase. The exception is B3-9; this formulation led to an almost phasepure pyrochlore with some rutile present.

The B3-9 formulation was intended to generate approximately 10 vol\% perovskite. Since this was not successful (see Table 3 and Figures A-11 and A12), a new formulation, B3-21, was defined that was based upon microprobe 
analysis data (provided by B. Ebbinghaus of LLNL) and image analysis of pertinent samples. This formulation did in fact yield significant amounts ( 6 vol\%) of perovskite within a pyrochlore matrix.

The B3-9 and B3-21 formulations yielded ceramics without brannerite or actinide oxide phases, even though the plutonium content of both of these formulations exceeded that contained in most or all other formulations. We believe this further supports the conclusion that the actinide oxide observed in these specimens is a reaction product rather than non-reacted precursor.

SEM micrographs of these specimens are shown in Appendix A: Figures A-7 and A-8 (B3-3); A-9 and A-10 (B3-4); A-11 and A-12 (B3-9); A-13 and A-14 (B3-11); A21 and $A-22(B 3-21)$.

\section{Glass Phase - B0-18}

The B0-18 samples were made to investigate a glass phase composition that was identified by microprobe analysis of silicon-containing ceramics. Amorphous monoliths were successfully produced but were susceptible to devitrification if not cooled sufficiently fast. Plutonium oxide crystals were observed in B0-18 samples that were slow-cooled from their processing temperature.

SEM micrographs of these specimens are shown in Appendix A, Figures A-23 and A-24.

\section{FUTURE WORK}

This report effectively completes fabrication and characterization of this series of formulations. Further work in this area will be defined to meet programmatic needs and to wrap up ICP-MS, He-pycnometry and XRD data.

During this course of experiments carbon contamination became of interest because of results from different $\mathrm{UO}_{2}$ stocks. A report describing experiments designed to investigate the effect of carbon in various forms and amounts is being compiled. This report will become available after the completion of a supplementary set of experiments that are intended to factor in relative scale of powder batches, which may greatly influence the overall effect of carbon contamination.

\section{ACKNOWLEDGMENTS}

The authors gratefully acknowledge the guidance and support of A. Bakel, M. Nole, J. Emery, P. Johnson, and D. Bowers. 


\section{REFERENCES}

1. S. G. Cochran, W. H. Danker, T. A. Edmunds, L. M. MacLean, and T. H. Gould, Fissile Material Disposition Program Final Immobilization Form Assessment and Recommendation, Lawrence Livermore National Laboratory, Livermore, CA, UCRL-ID-128705 (October 3, 1997).

2. W. D. Kingery, H. K. Bowen, and D. R. Uhlman, Introduction to Ceramics, $2^{\text {nd }}$ Edition, New York, John Wiley \& Sons, Inc. (1976).

3. A. J. Bakel, V. N. Zyryanov, C. J. Mertz, E. C. Buck, and D. B. Chamberlain, Hf-Ce-U Impurity Report, (Draft, June 1999). 
Appendix A. Scanning Electron Photomicrographs 



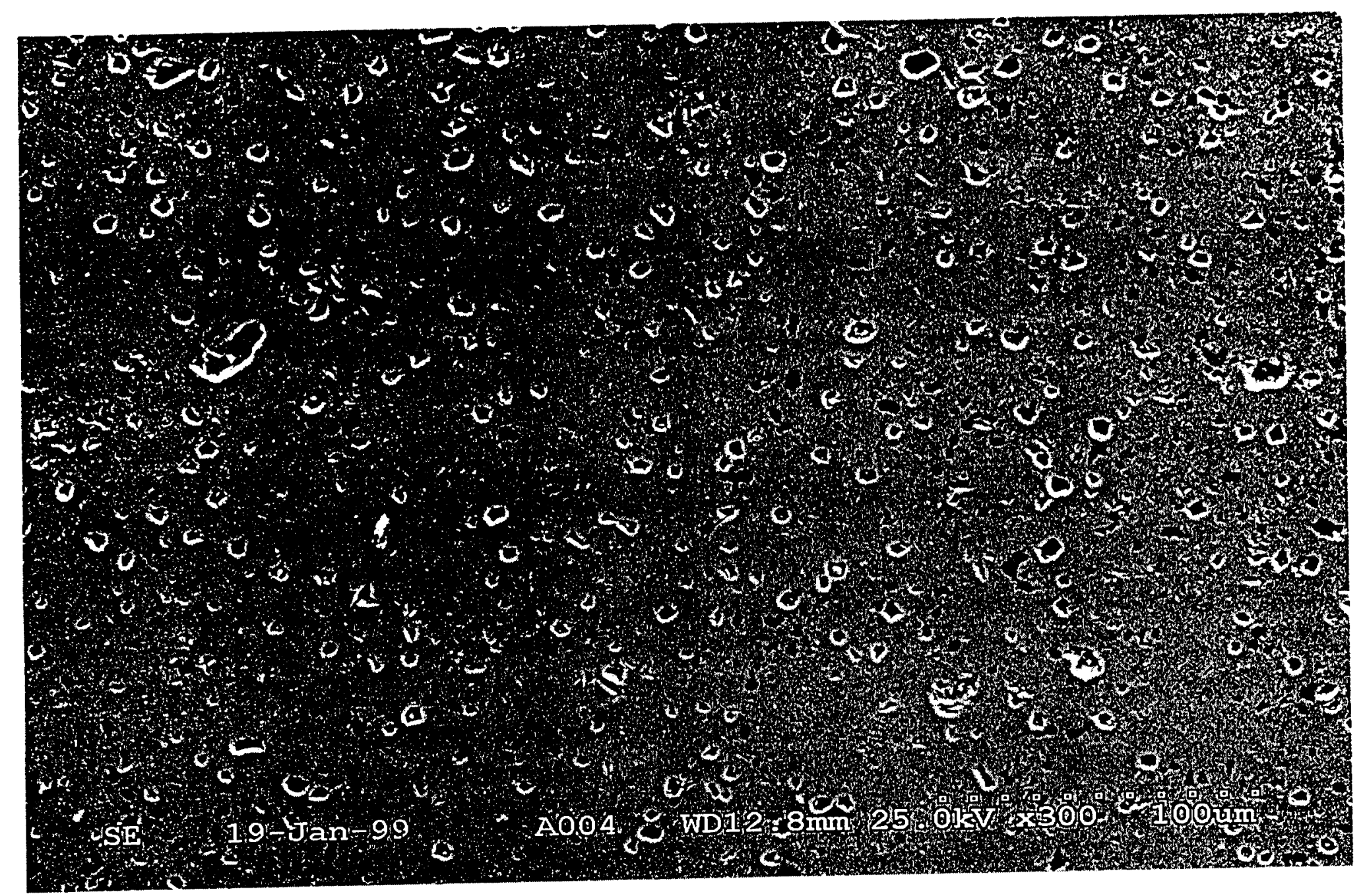

Figure A-1. Secondary Electron Image of A0 Specimen (300X) 


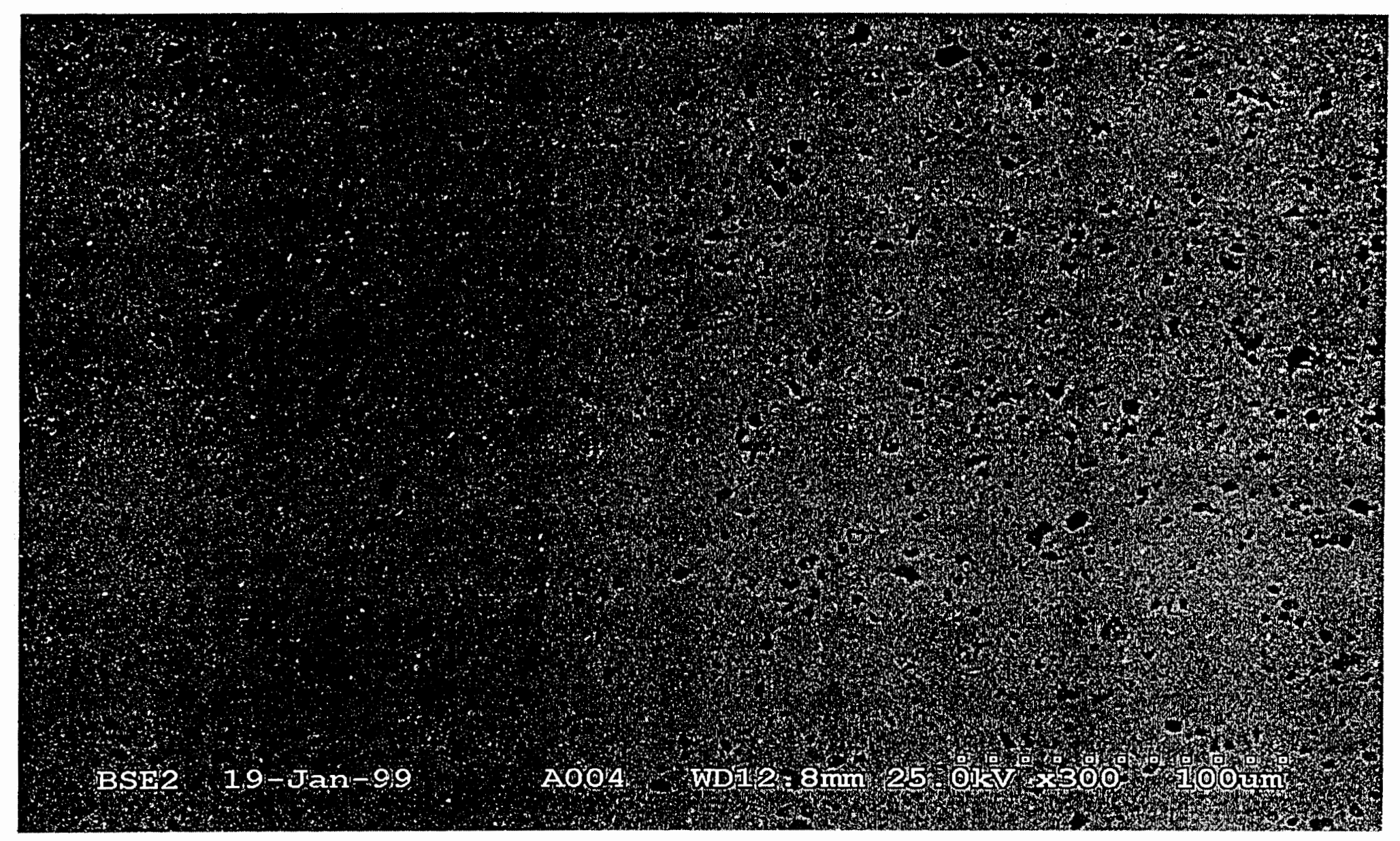

Figure A-2. Backscattered Electron Image of A0 Specimen (300X) 


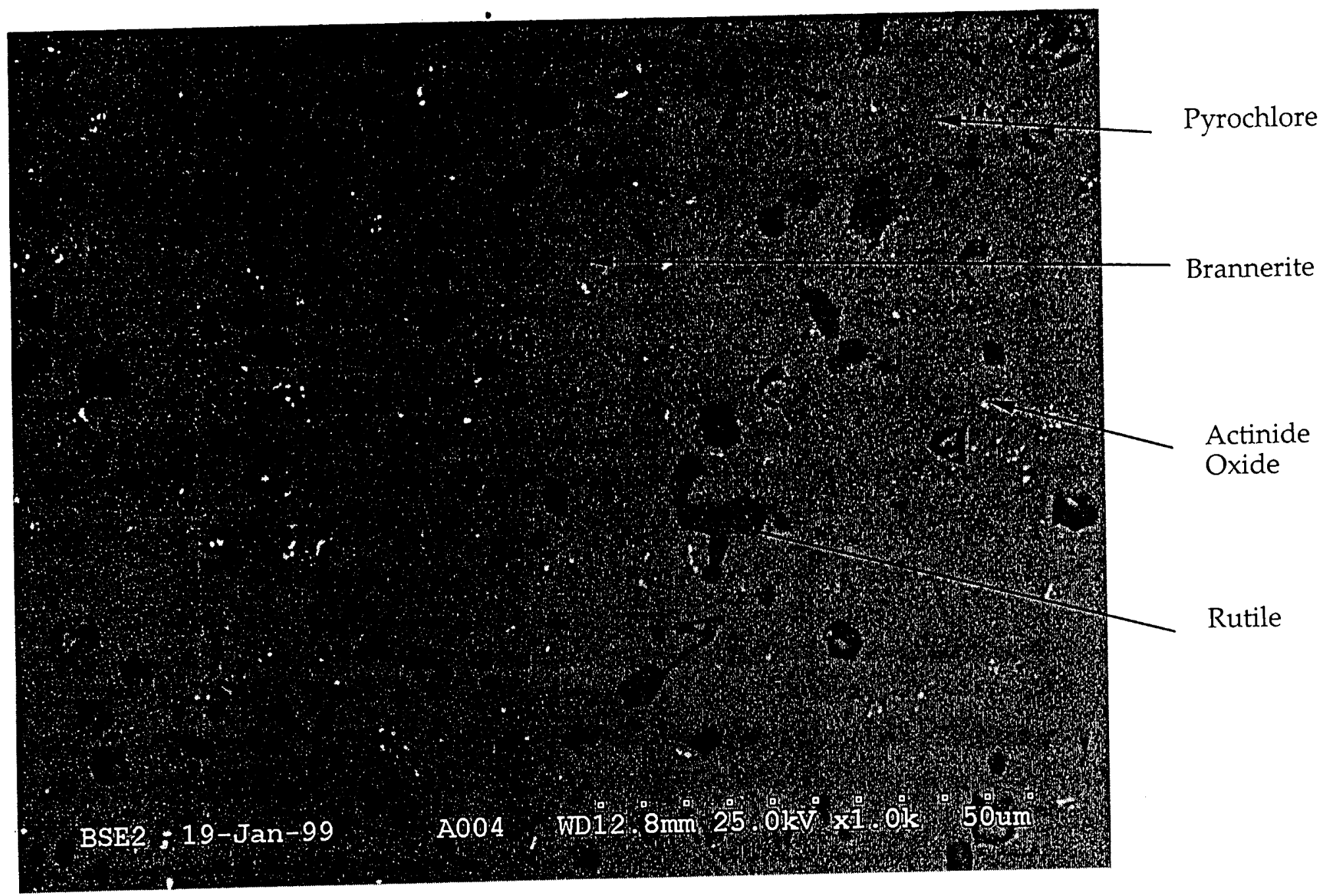

Figure A-3 Backscattered Electron Image of A0 Specimen (1000X) 


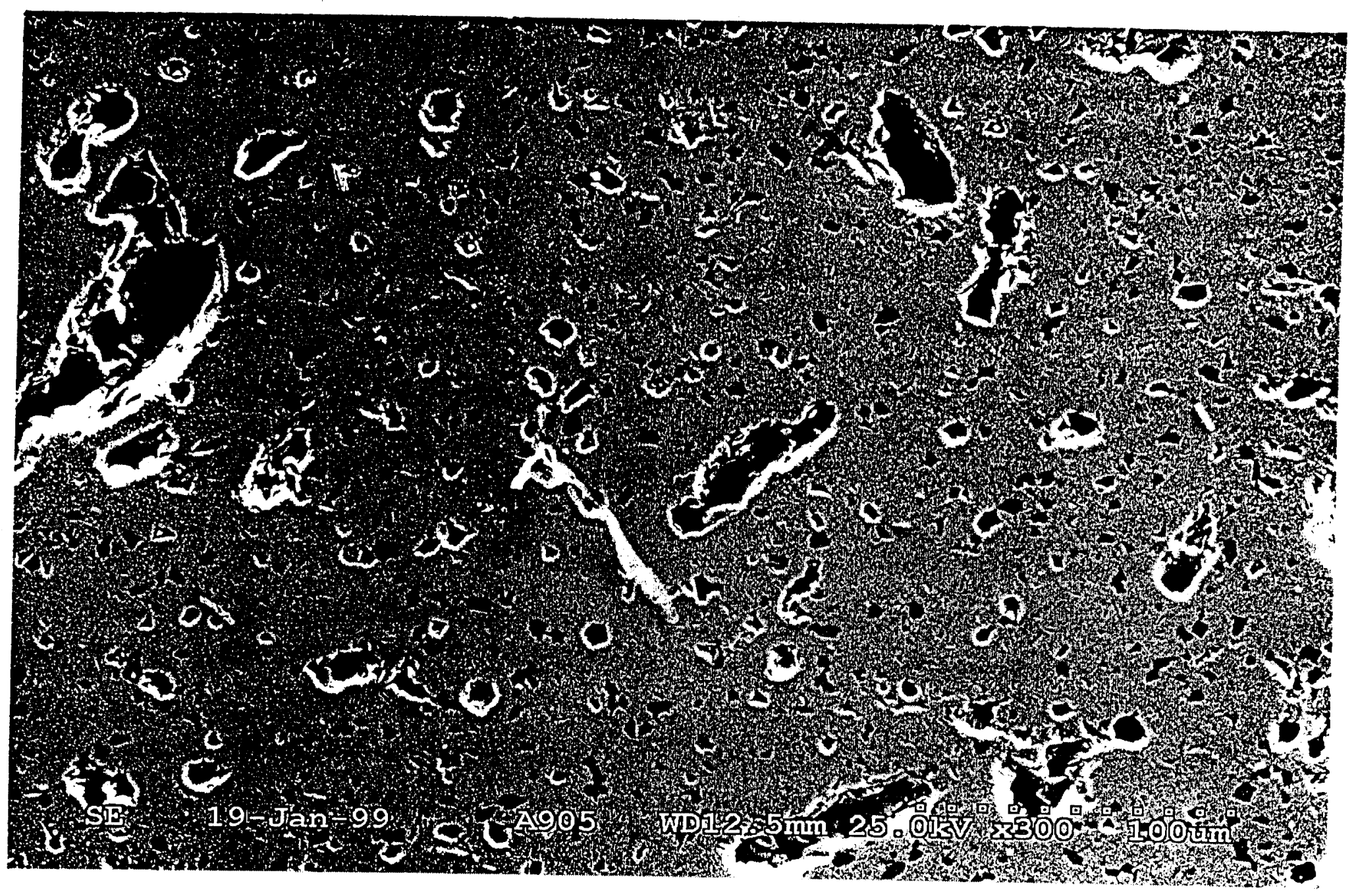

Figure A-4. Secondary Electron Image of A9 Specimen (300X) 


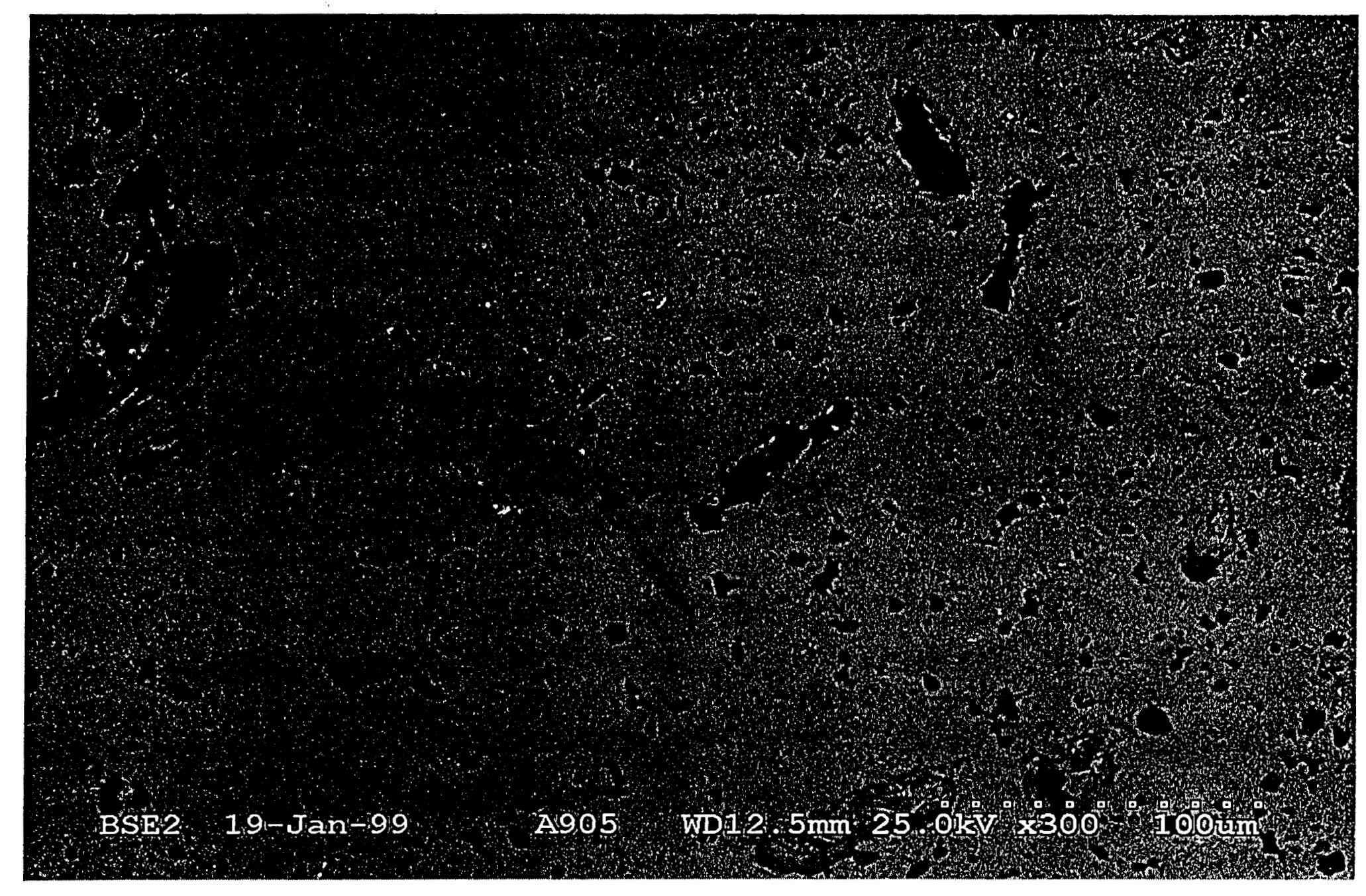

Figure A-5. Backscattered Electron Image of A9 Specimen (300X) 


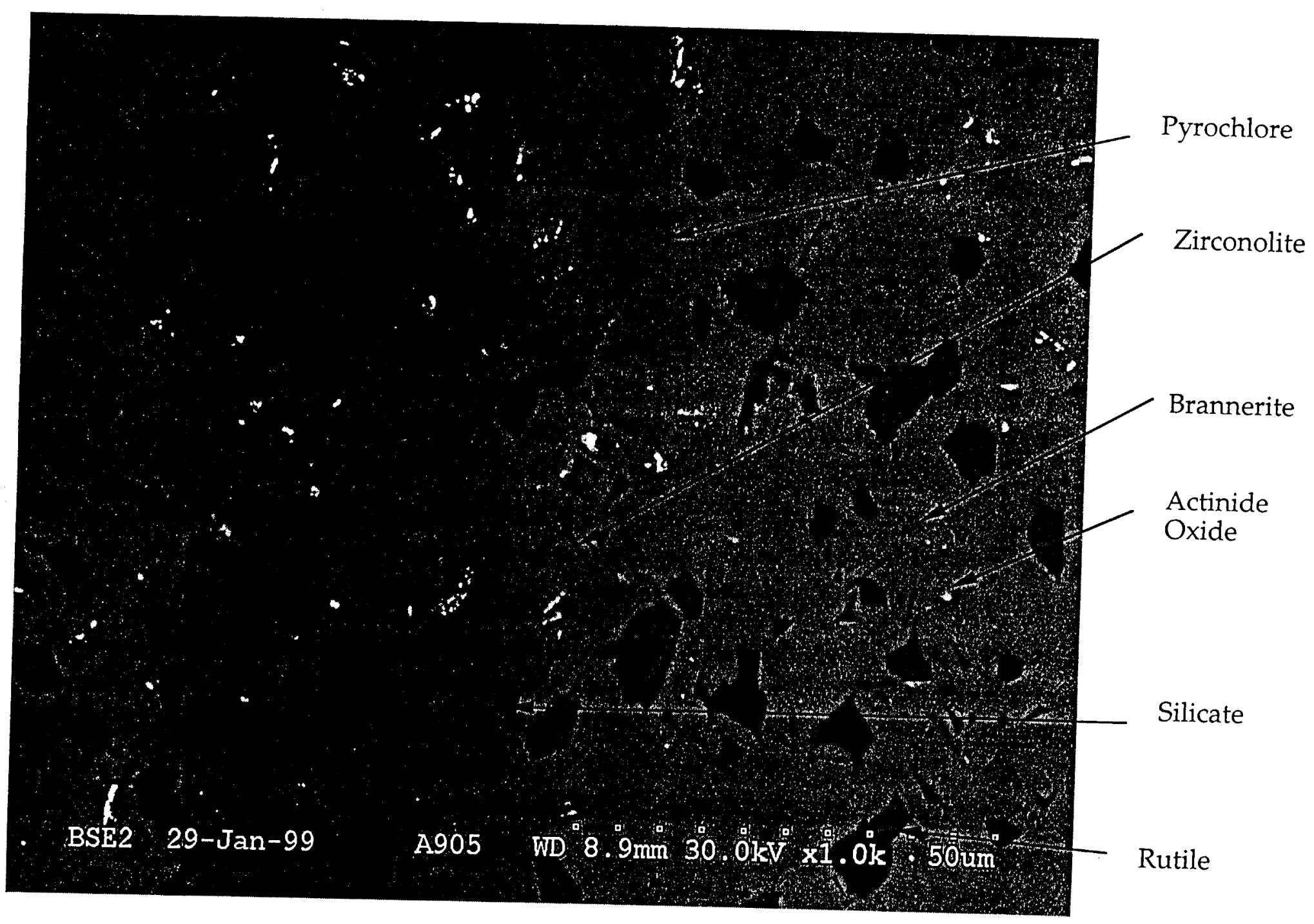

Figure A-6. Backscattered Electron Image of A9 Specimen (1000X) 


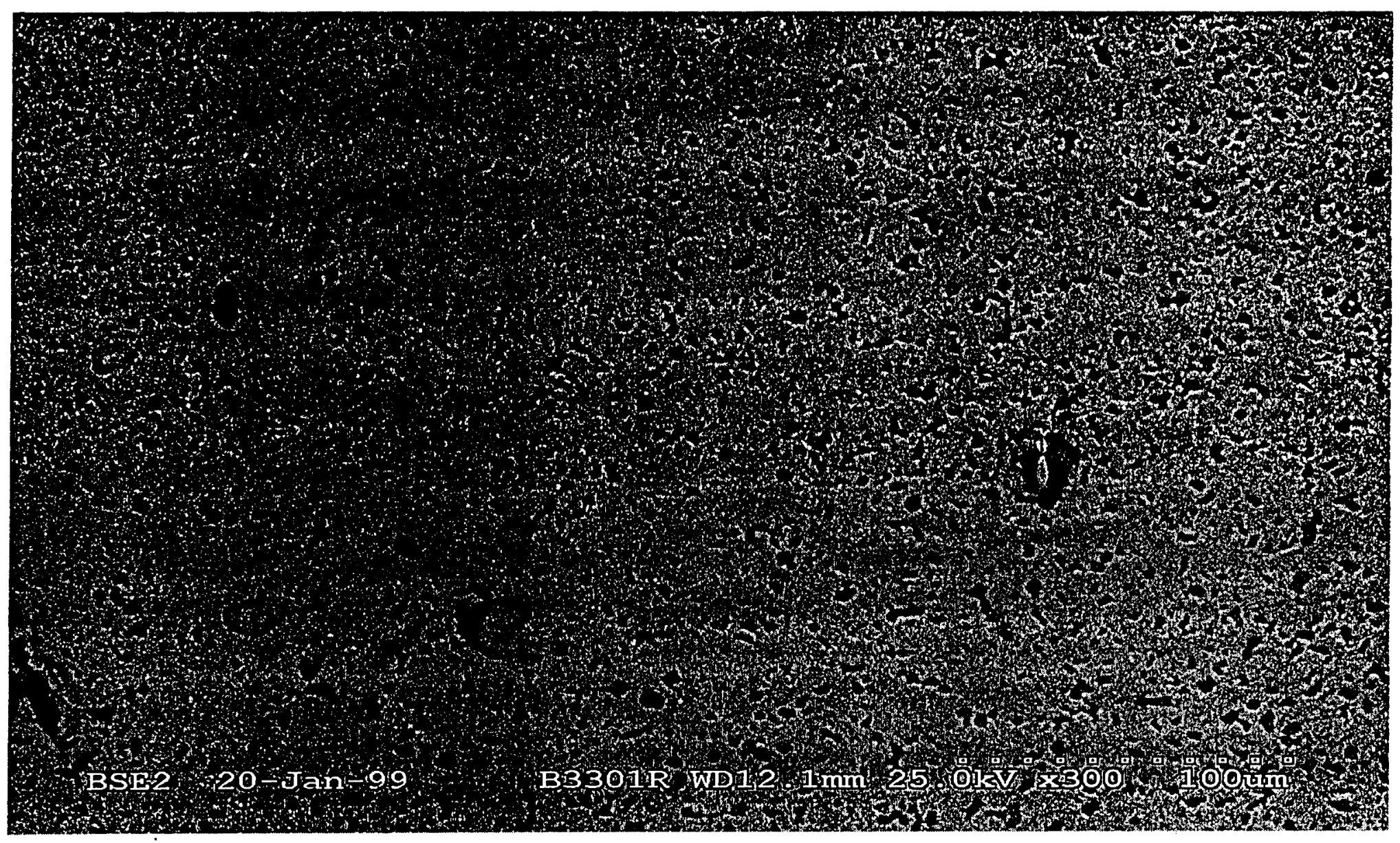

Figure A-7. Backscattered Electron Image of B3-3 Specimen (300X) 


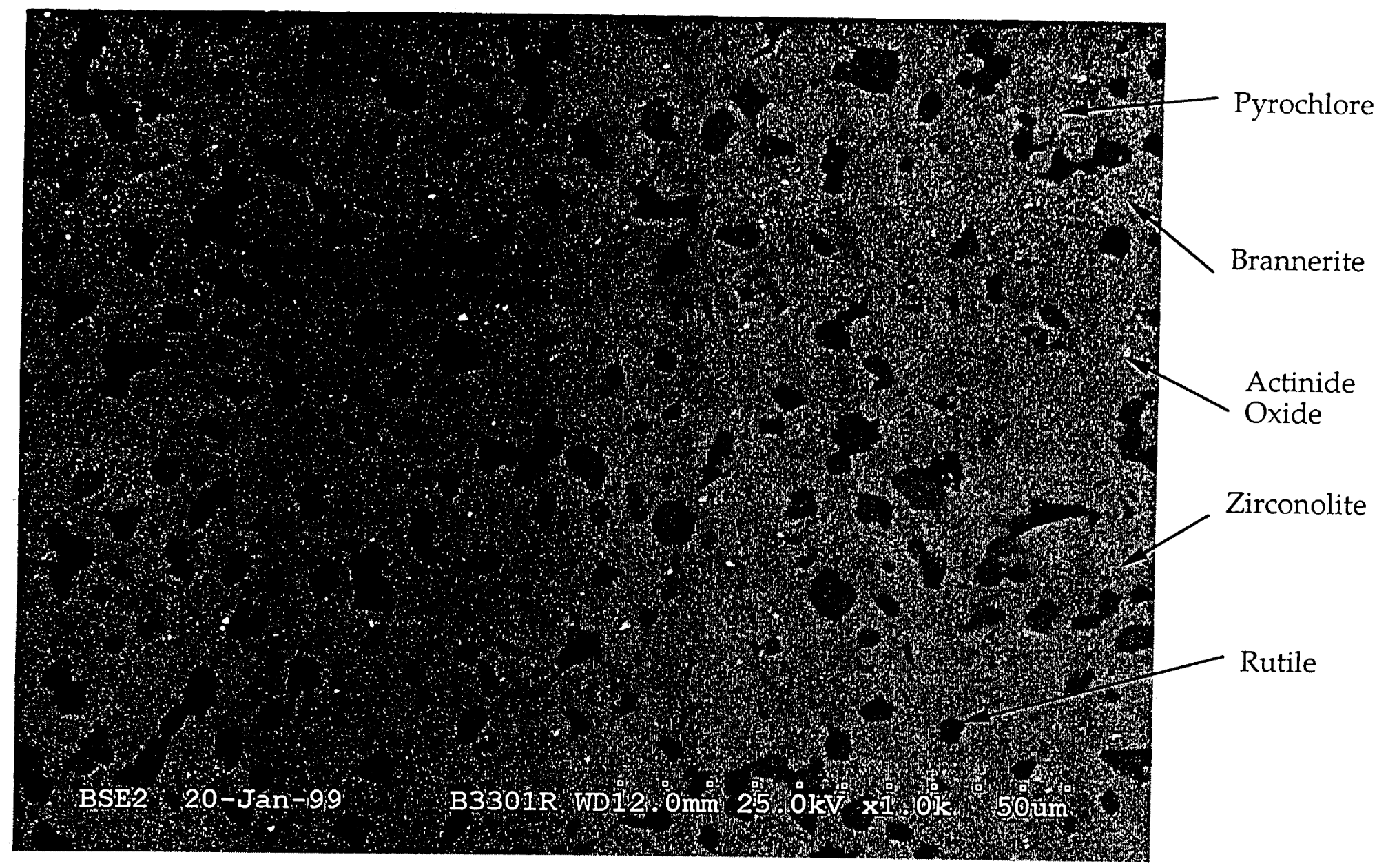

Figure A-8. Backscattered Electron Image of B3-3 Specimen (1000X) 


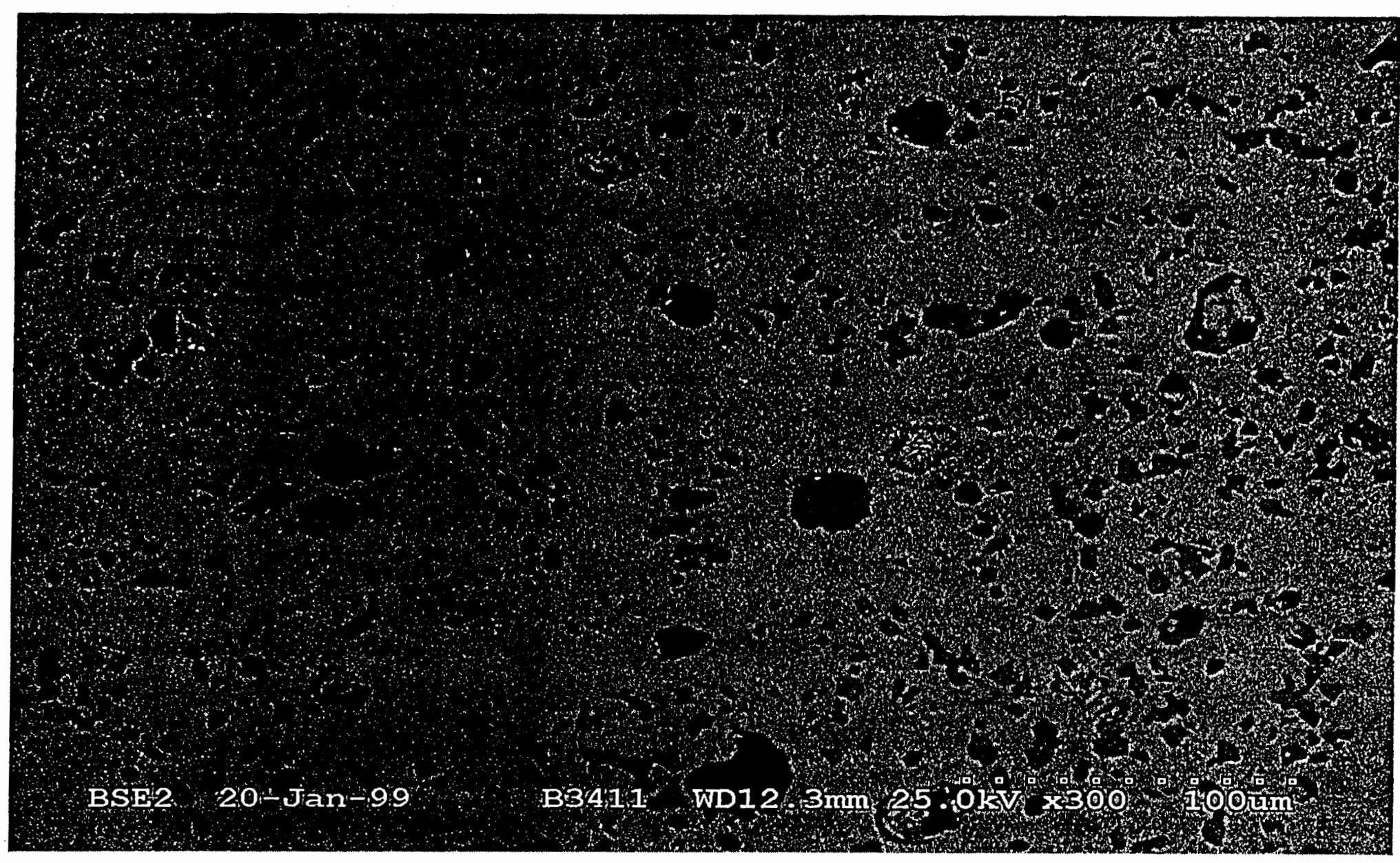

Figure A-9. Backscattered Electron Image of B3-4 Specimen (300X) 


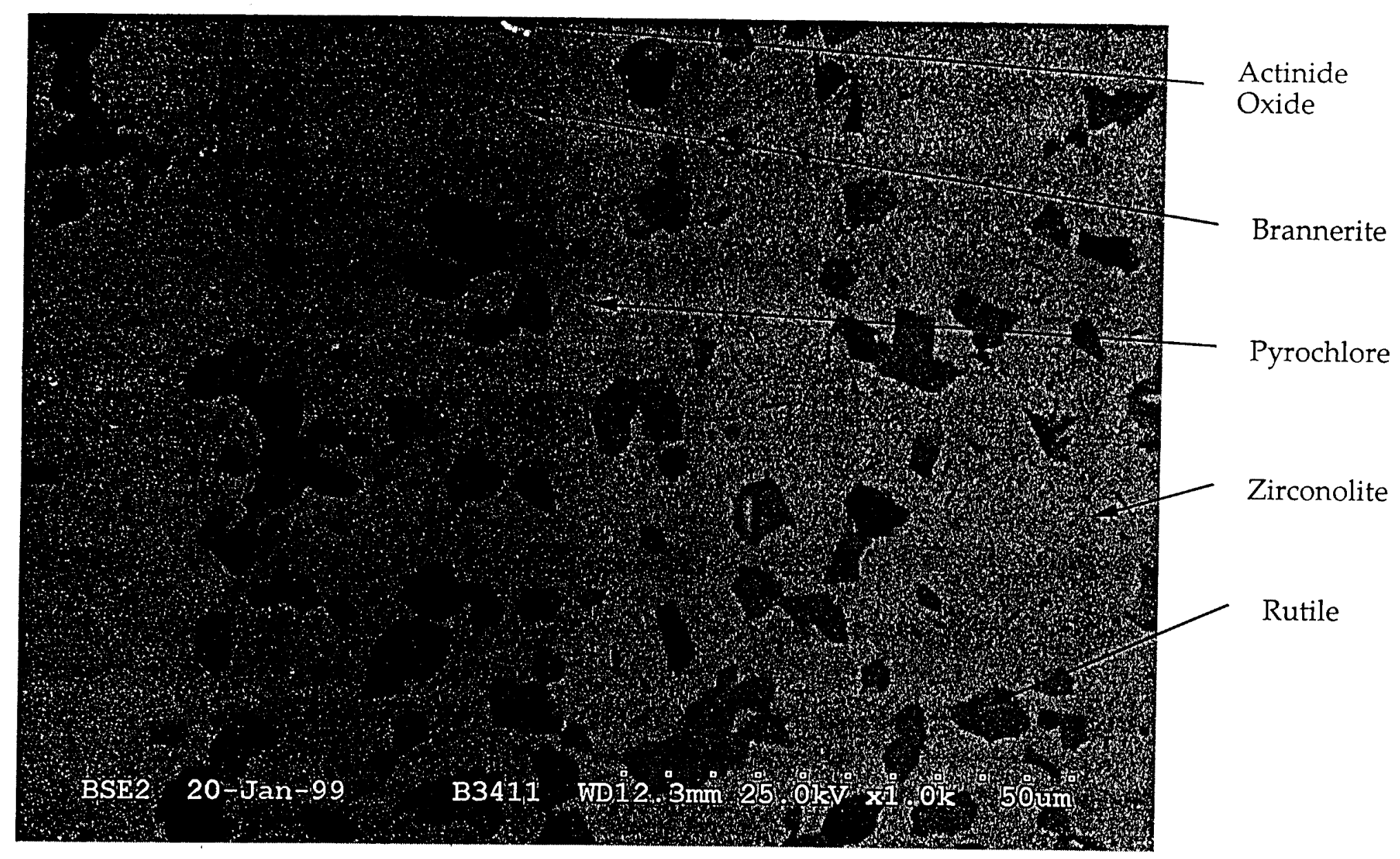

Figure A-10. Backscattered Electron Image of B3-4 Specimen (1000X) 


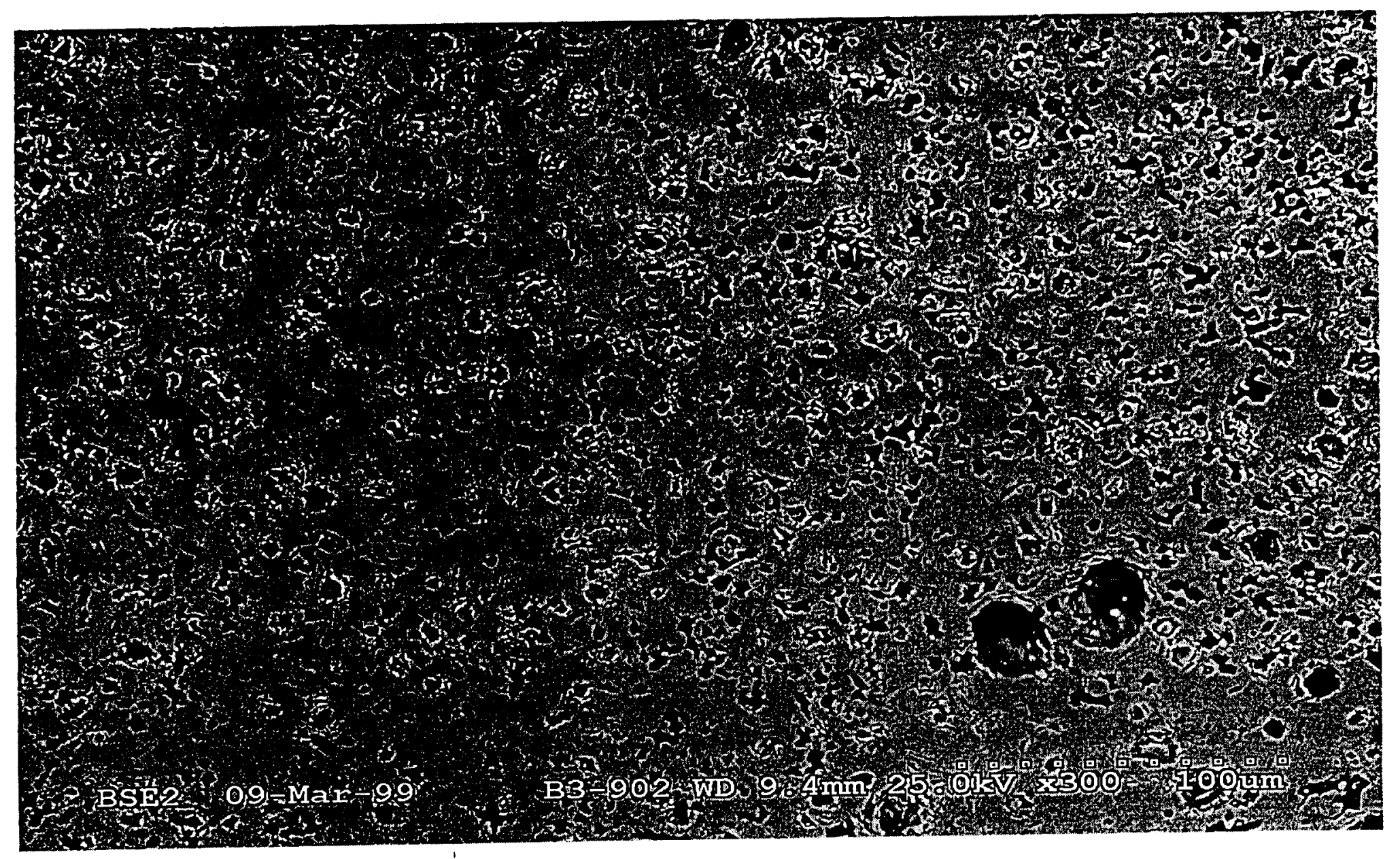

Figure A-11. Backscattered Electron Image of B3-9 Specimen (300X) 


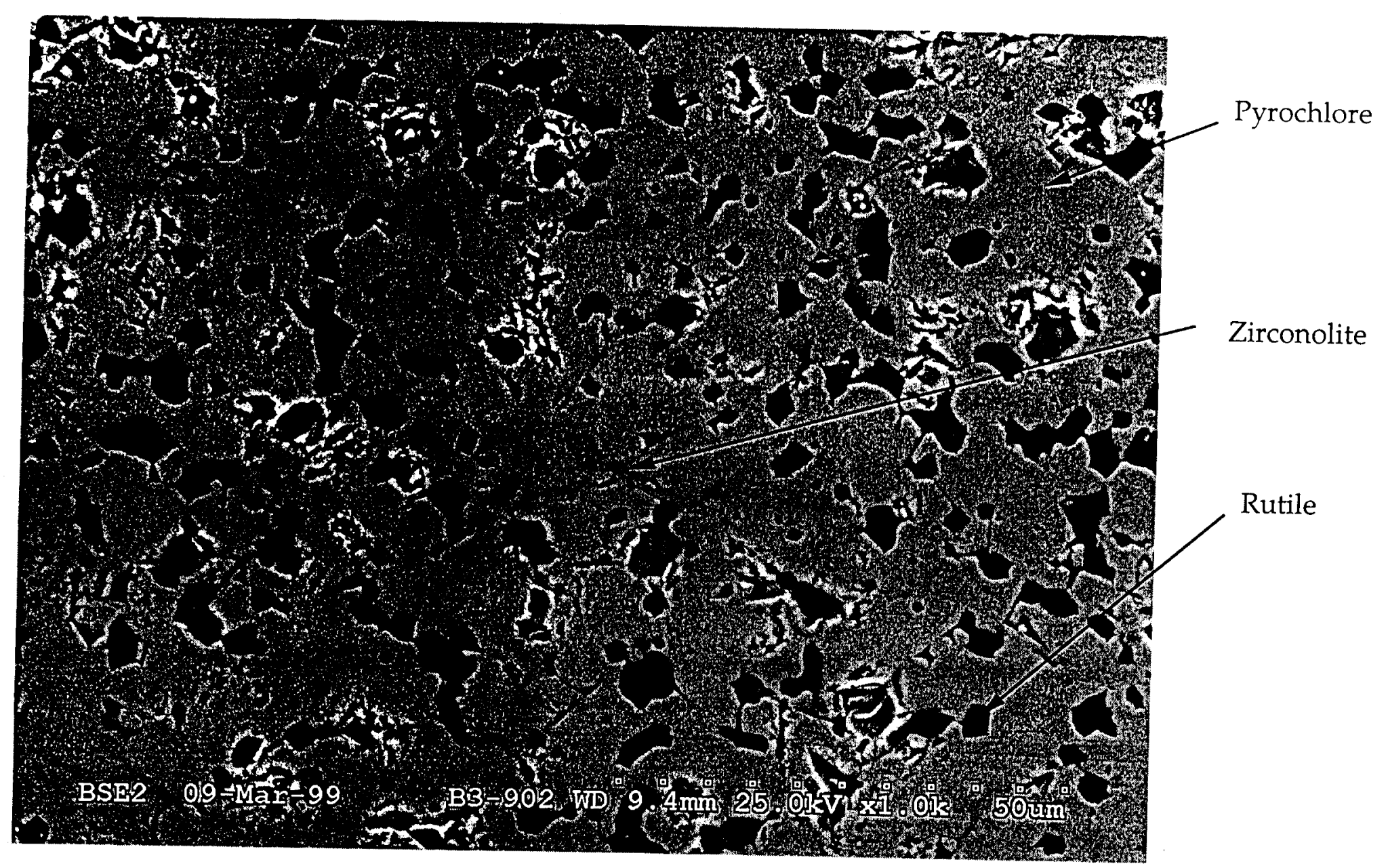

Figure A-12. Backscattered Electron Image of B3-9 Specimen (1000X) 


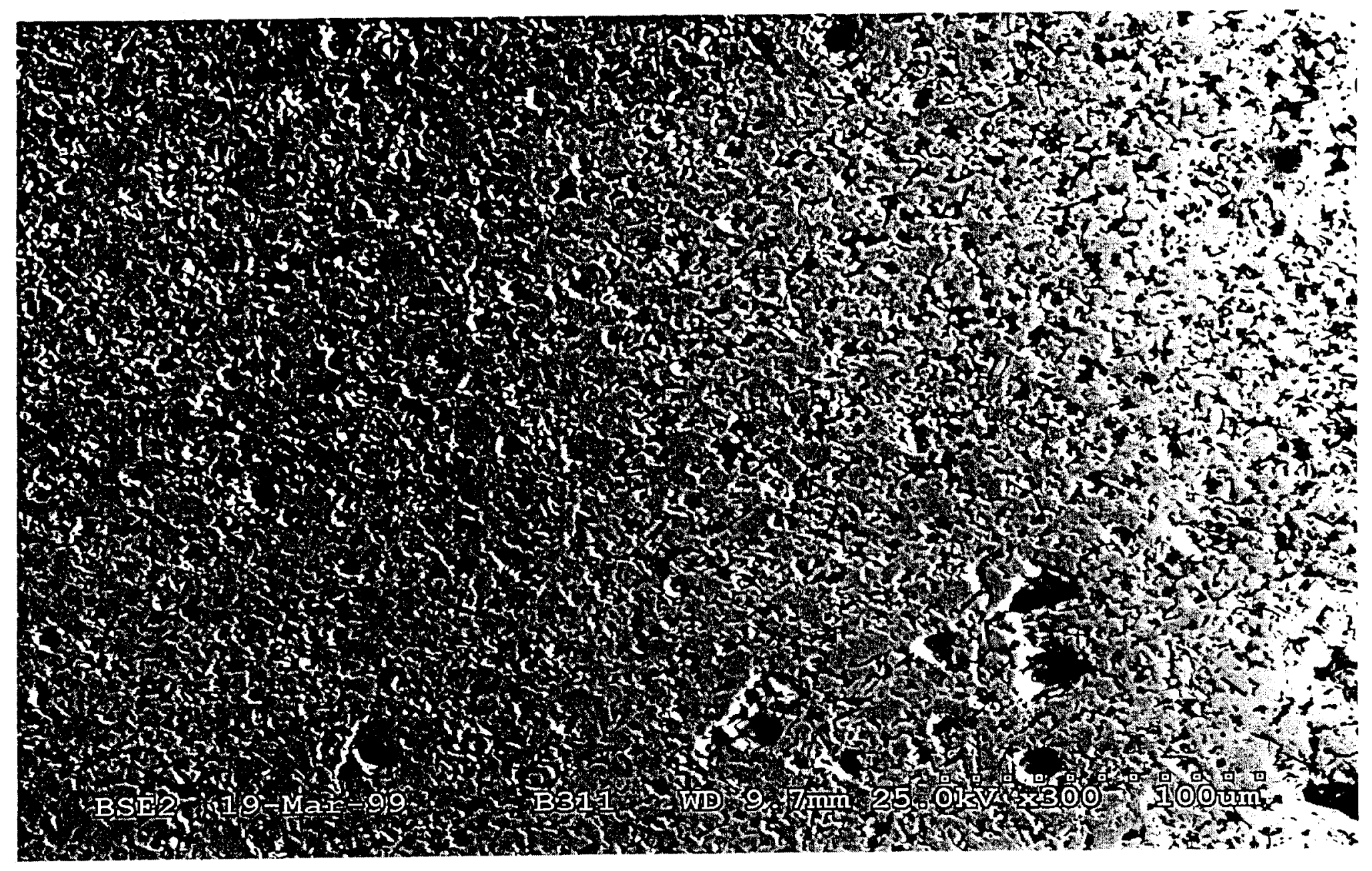

Figure A-13. Backscattered Electron Image of B3-11 Specimen (300X) 


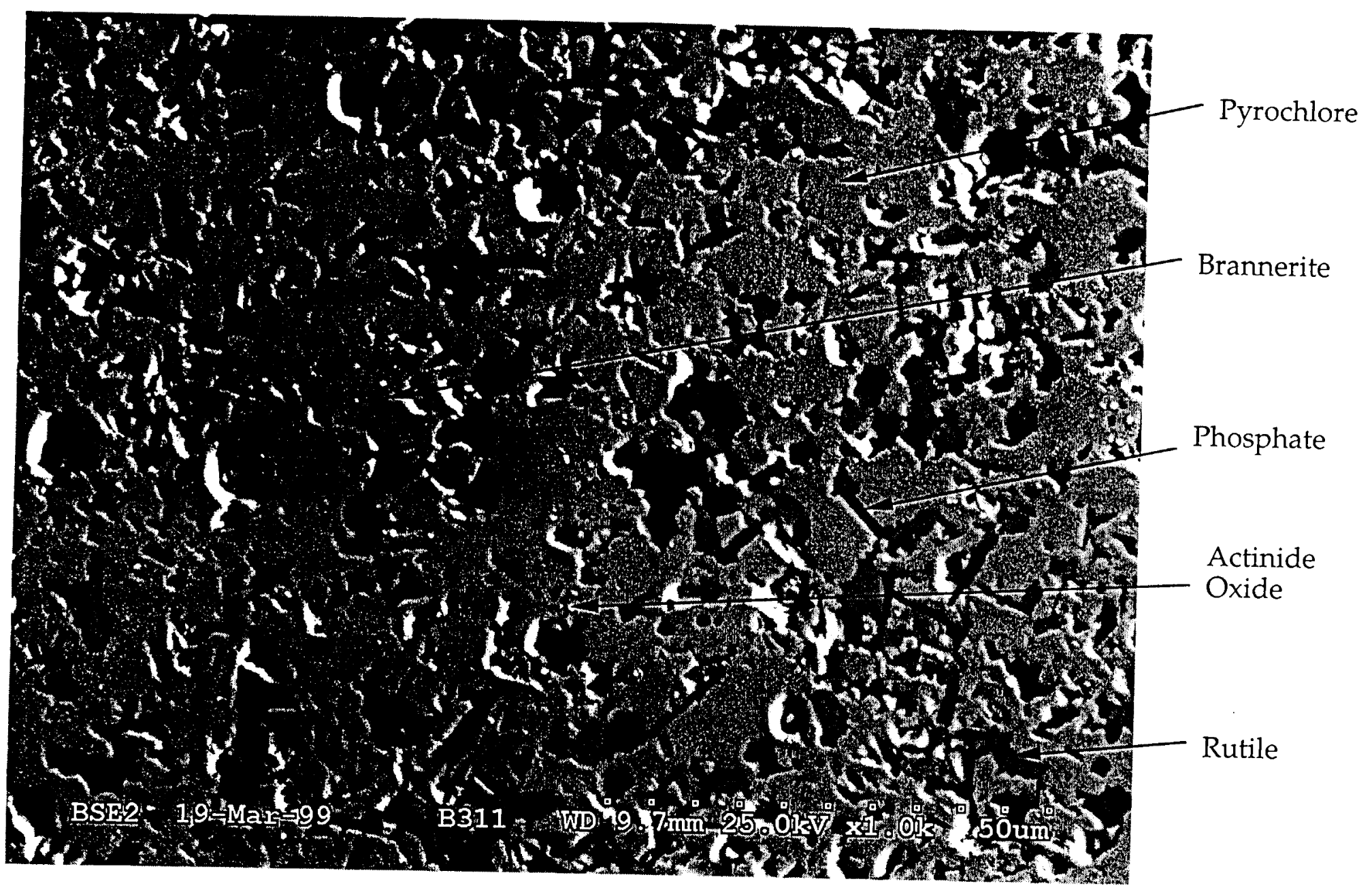

Figure A-14. Backscattered Electron Image of B3-11 Specimen (1000X) 


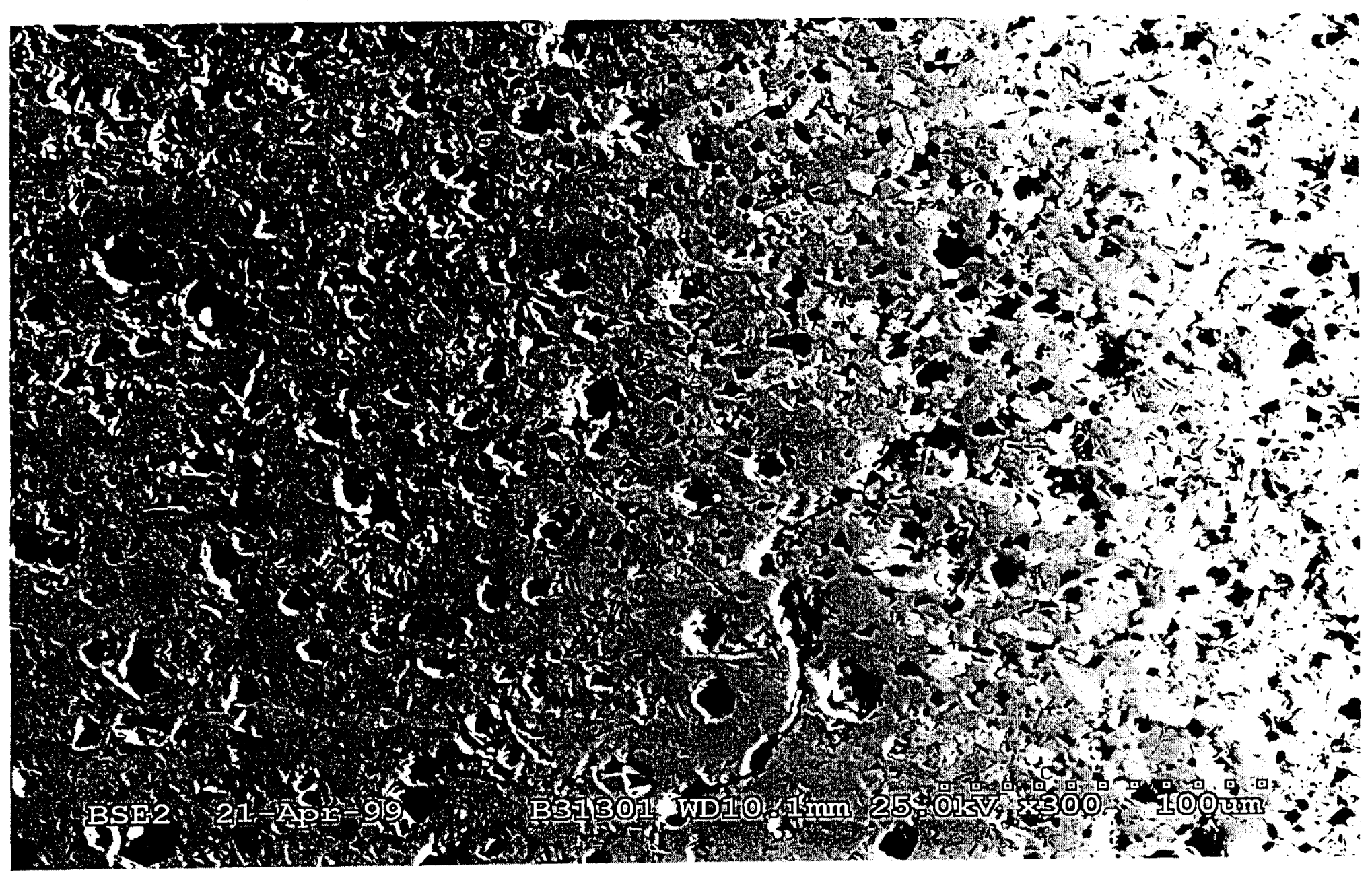

Figure A-15. Backscattered Electron Image of B3-13 Specimen (300X) 


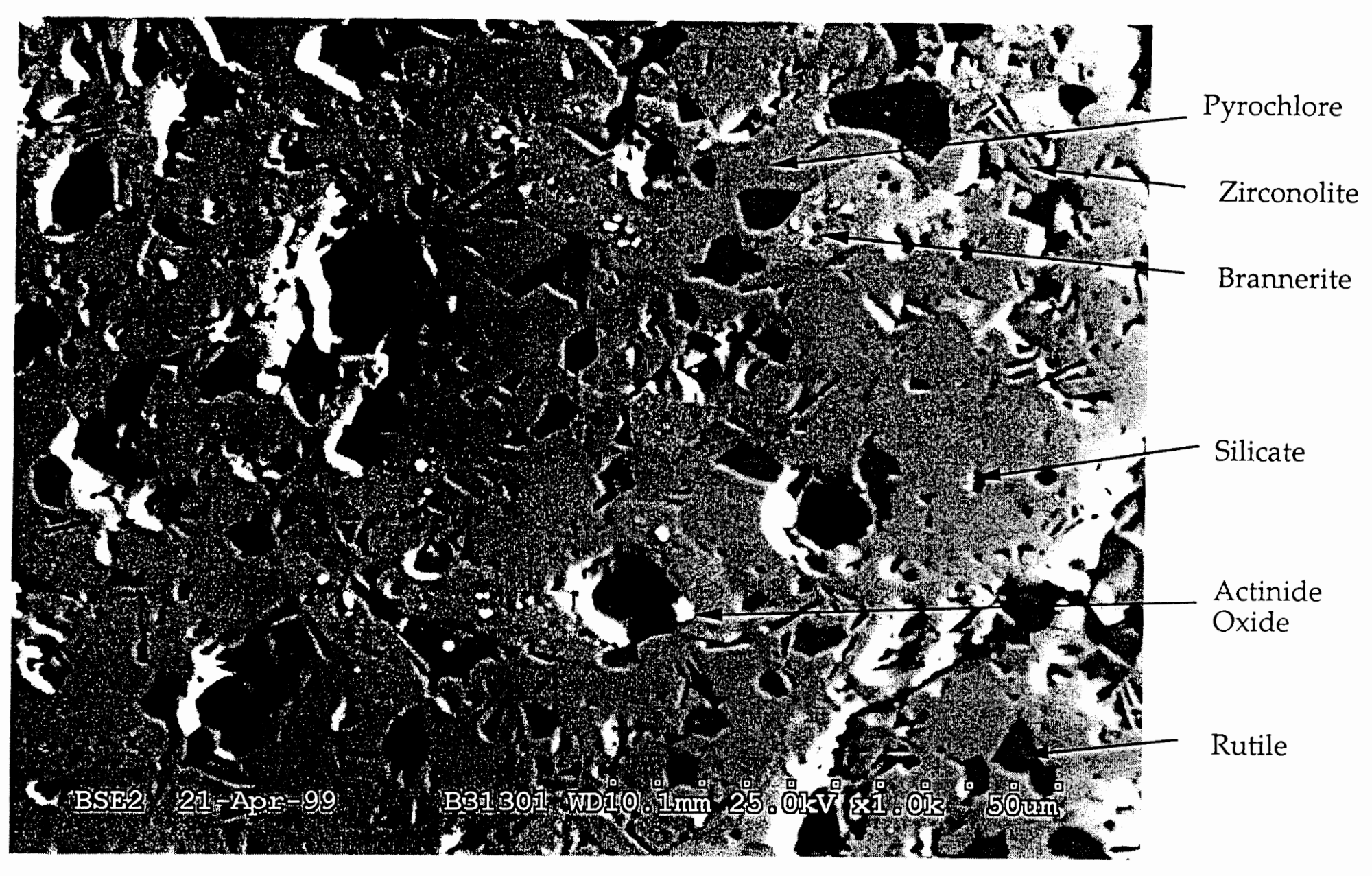

Figure A-16. Backscattered Electron Image of B3-13 Specimen (1000X) 


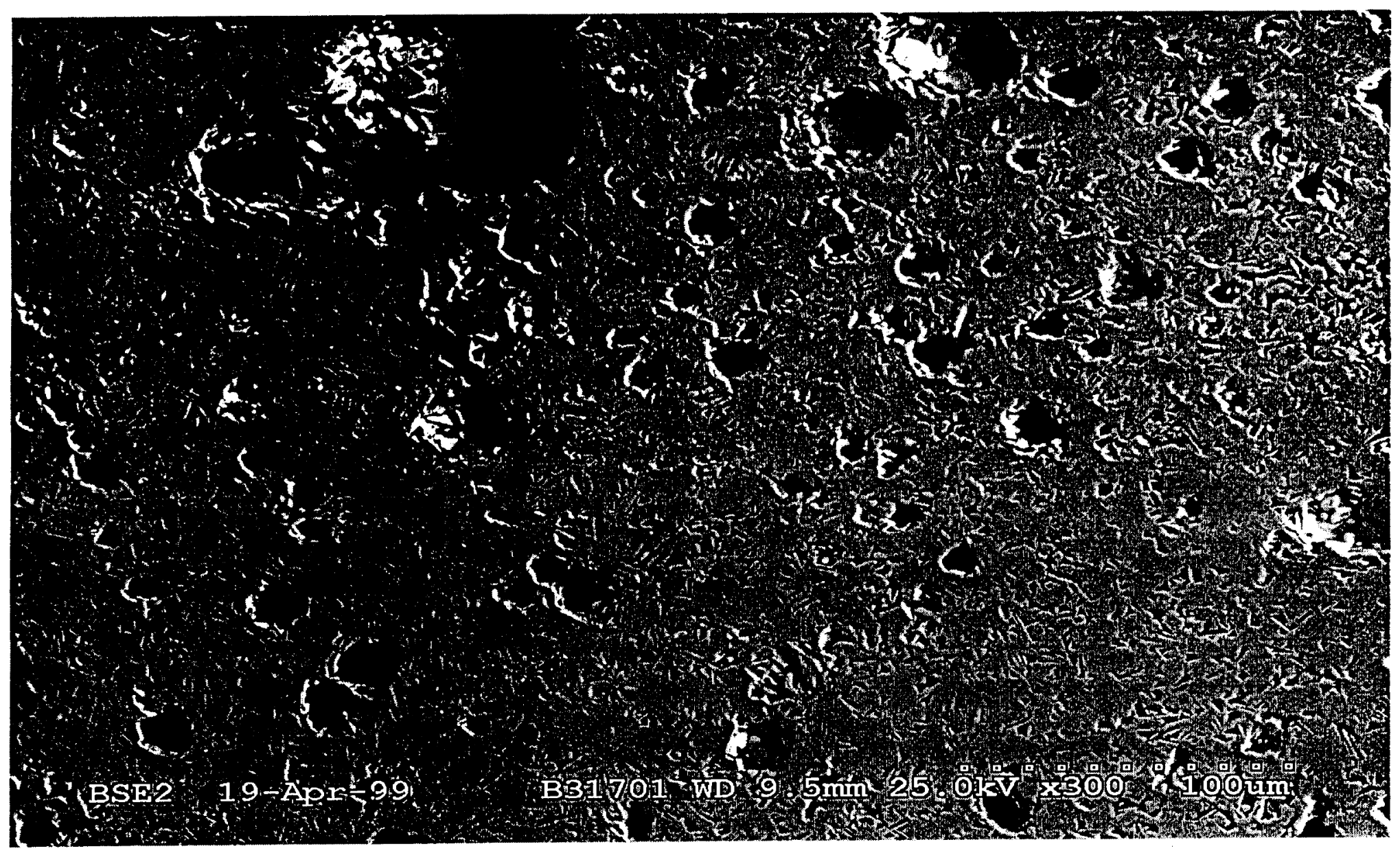

Figure A-17. Backscattered Electron Image of B3-17 Specimen (300X) 


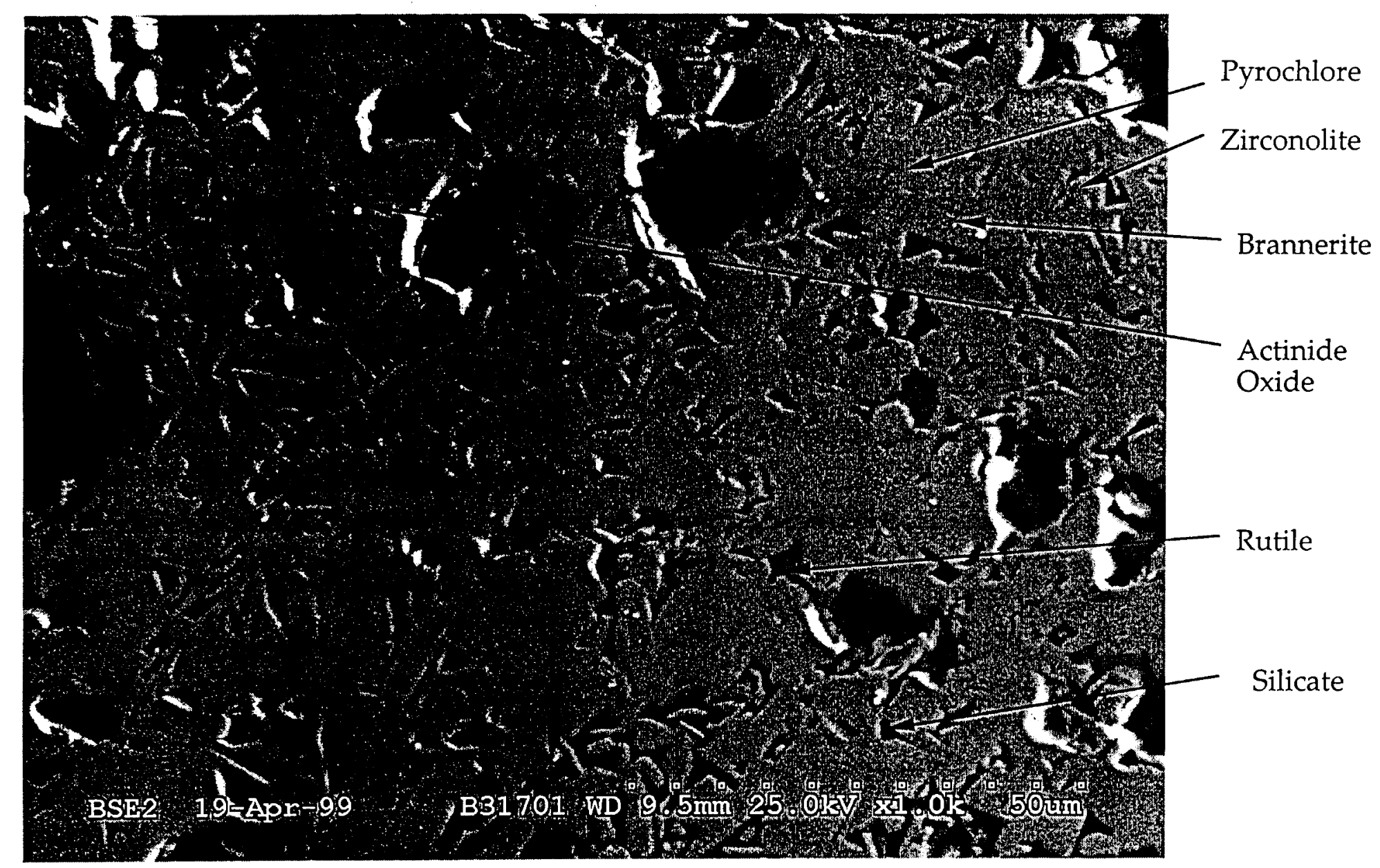

Figure A-18. Backscattered Electron Image of B3-17 Specimen (1000X) 


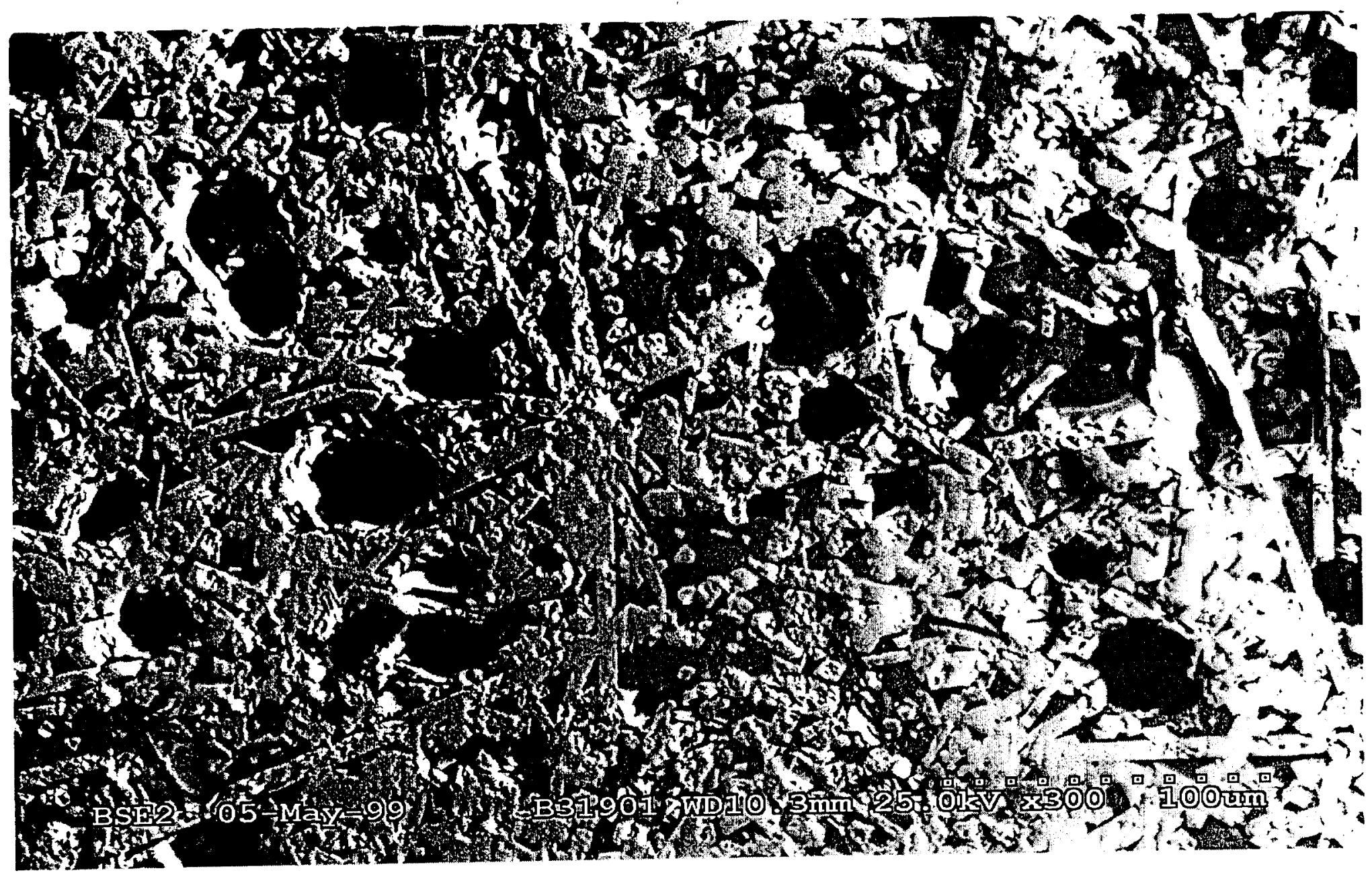

Figure A-19. Backscattered Electron Image of B3-19 Specimen (300X) 


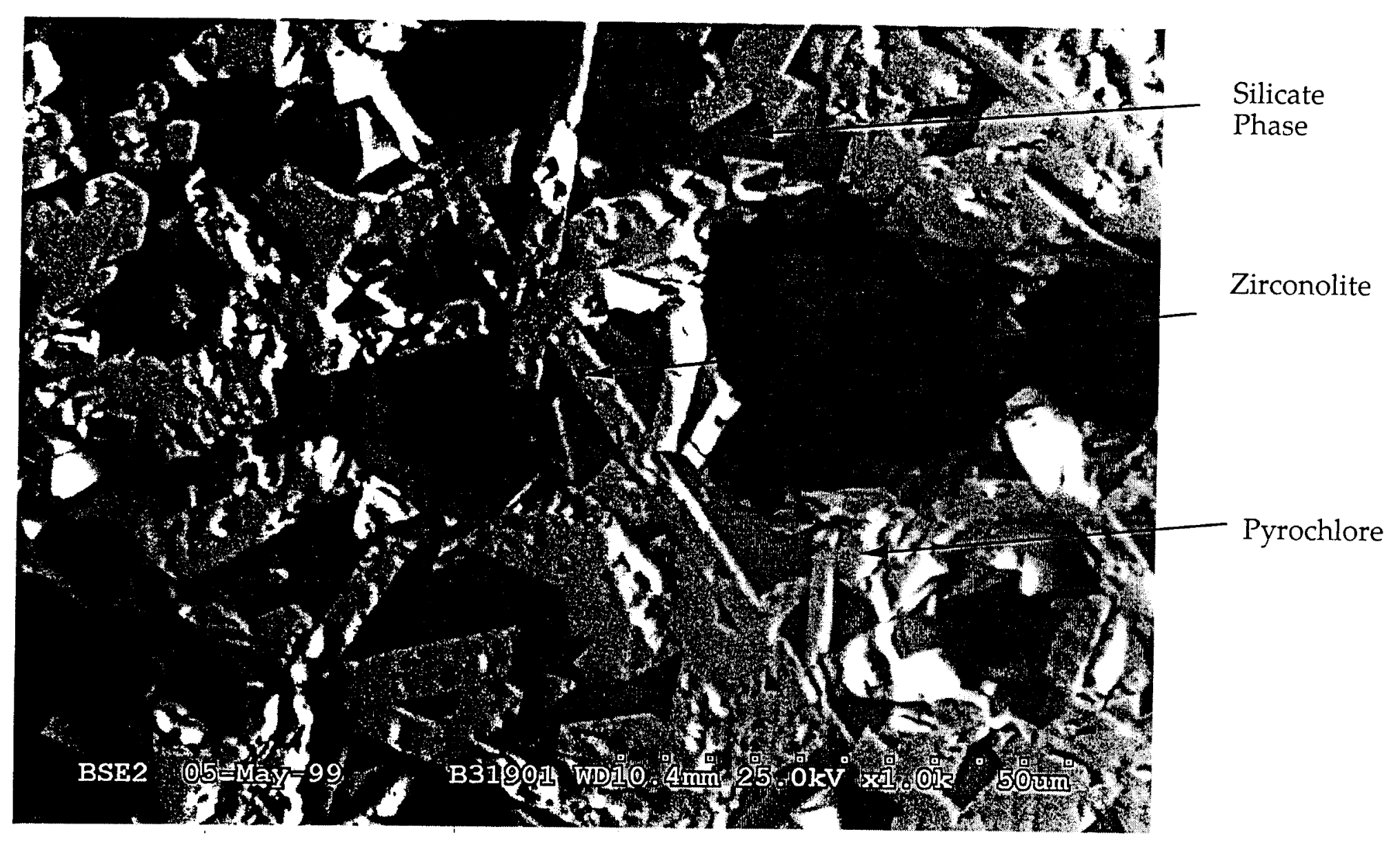

Figure A-20. Backscattered Electron Image of B3-19 Specimen (1000X) 


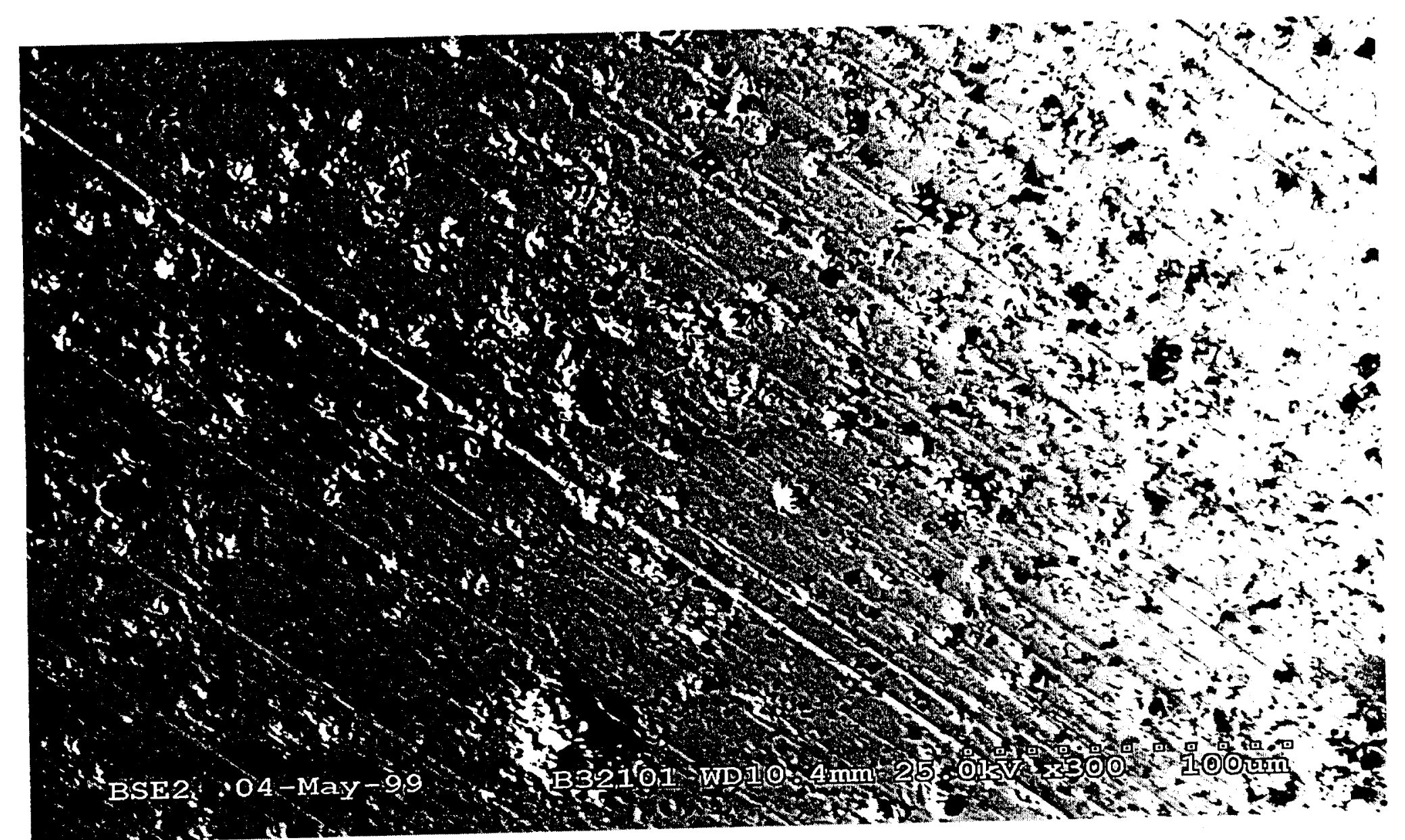

Figure A-21. Backscattered Electron Image of B3-21 Specimen (300X) 


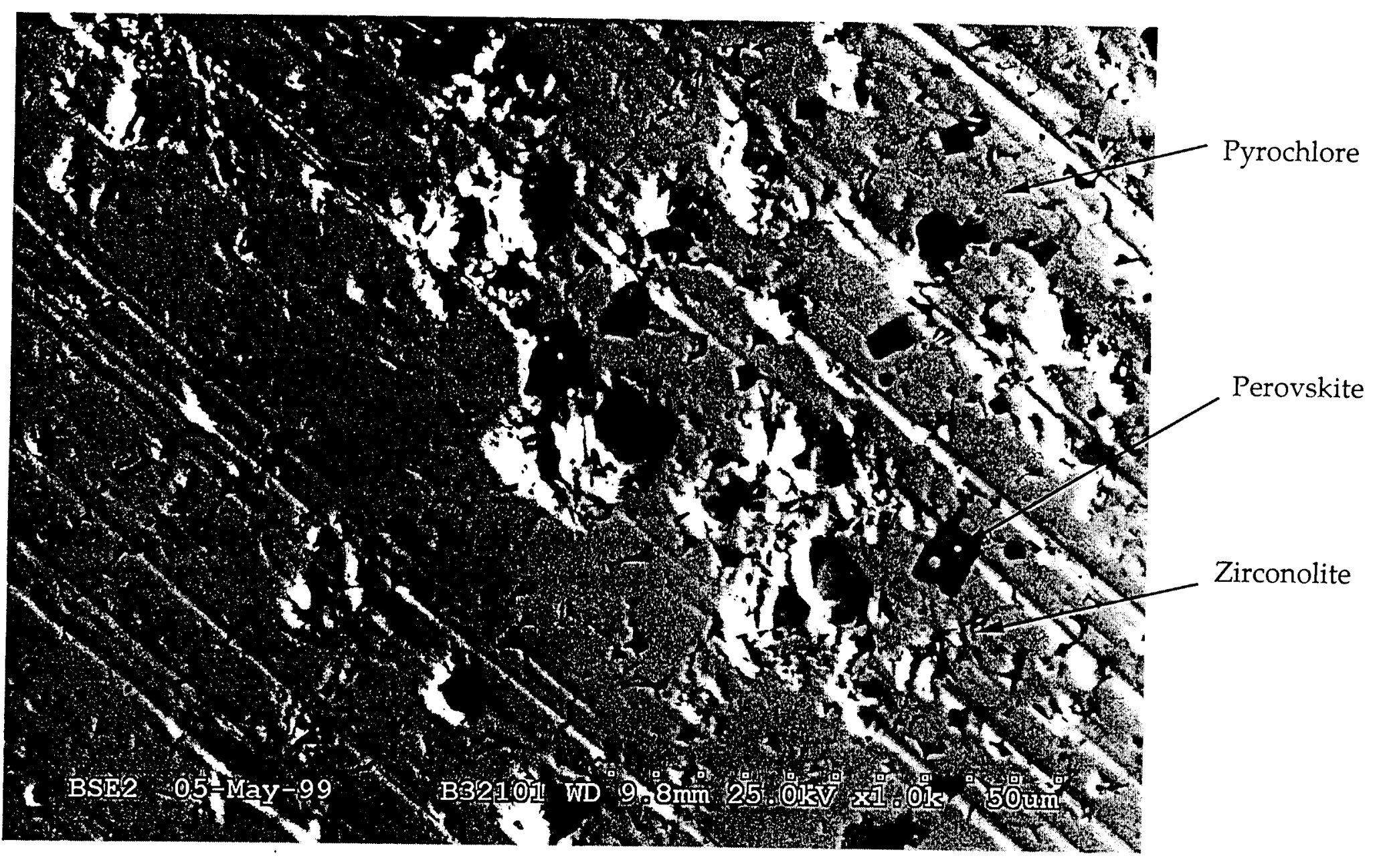

Figure A-22. Backscattered Electron Image of B3-21 Specimen (1000X) 


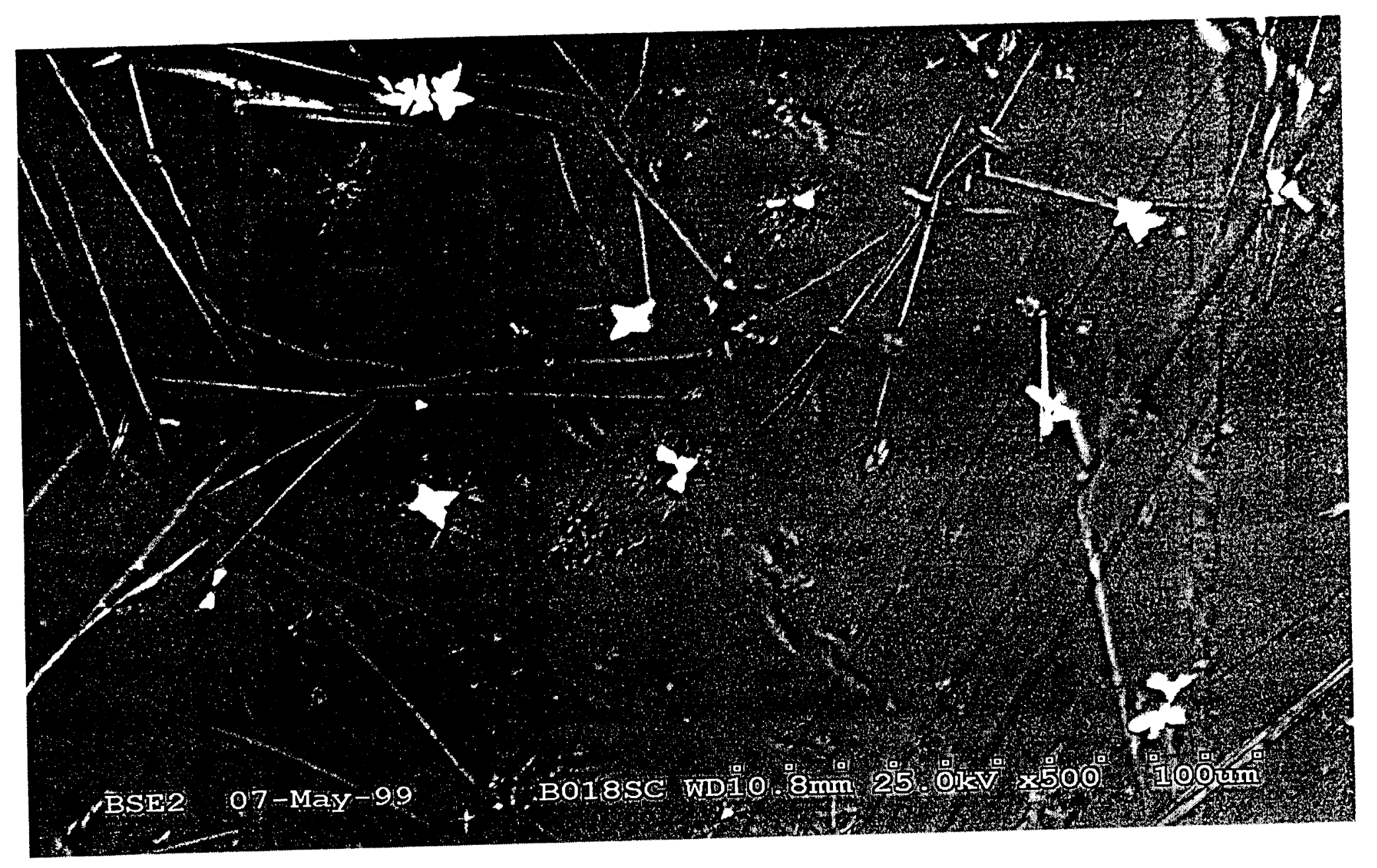

Figure A-23. Backscattered Electron Image of B0-18 Specimen after Slow Cooling (500X) 


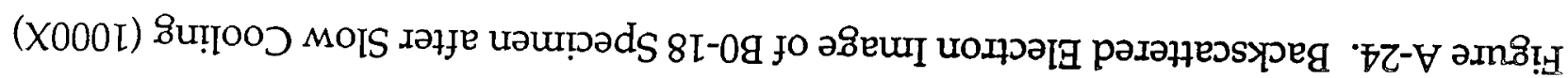

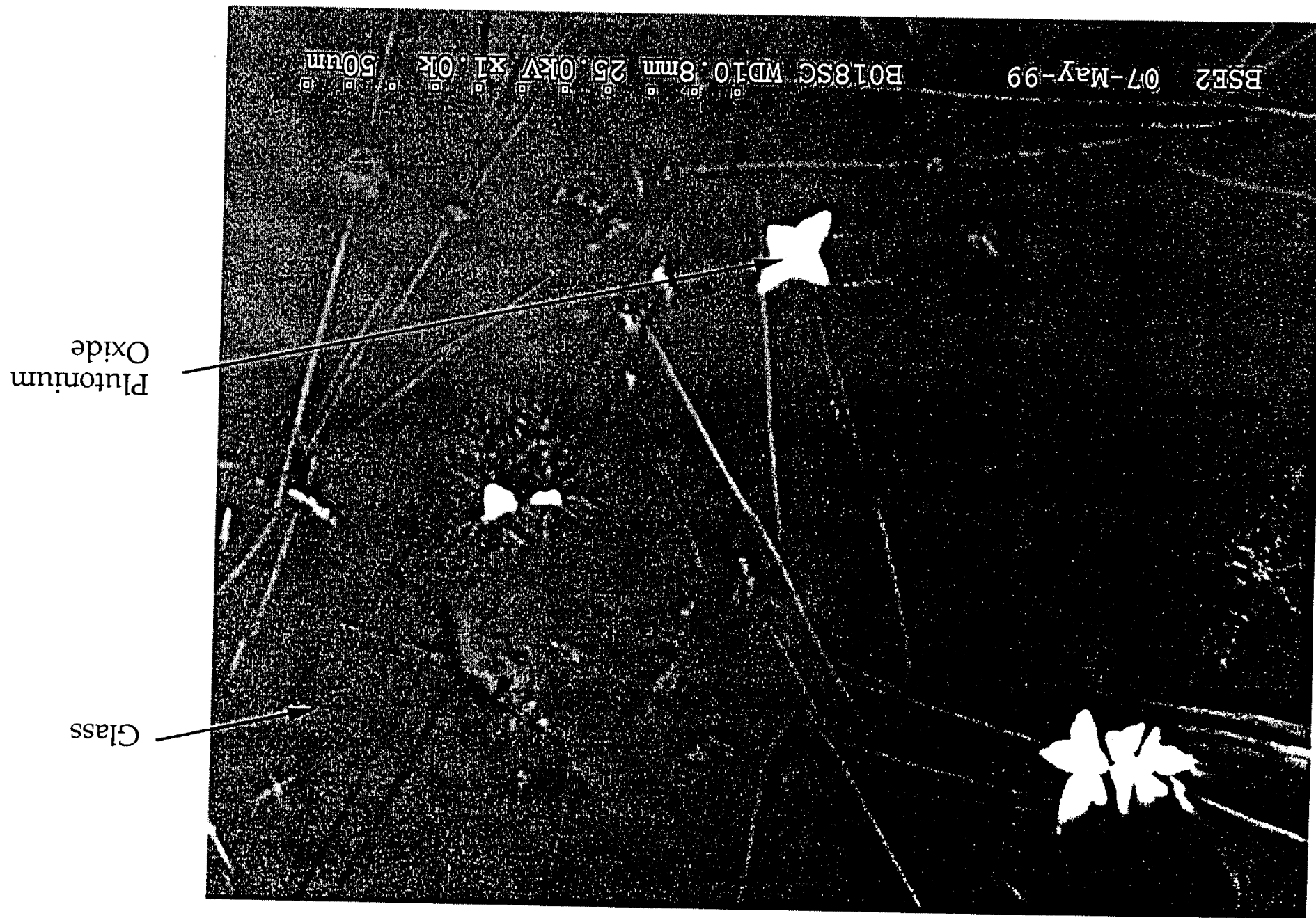


Appendix B. Select Powder X-Ray Diffraction Patterns 

Figure B-1. Powder $\times$-Ray Diffraction Pattern of A0 Sample Sintered in Argon

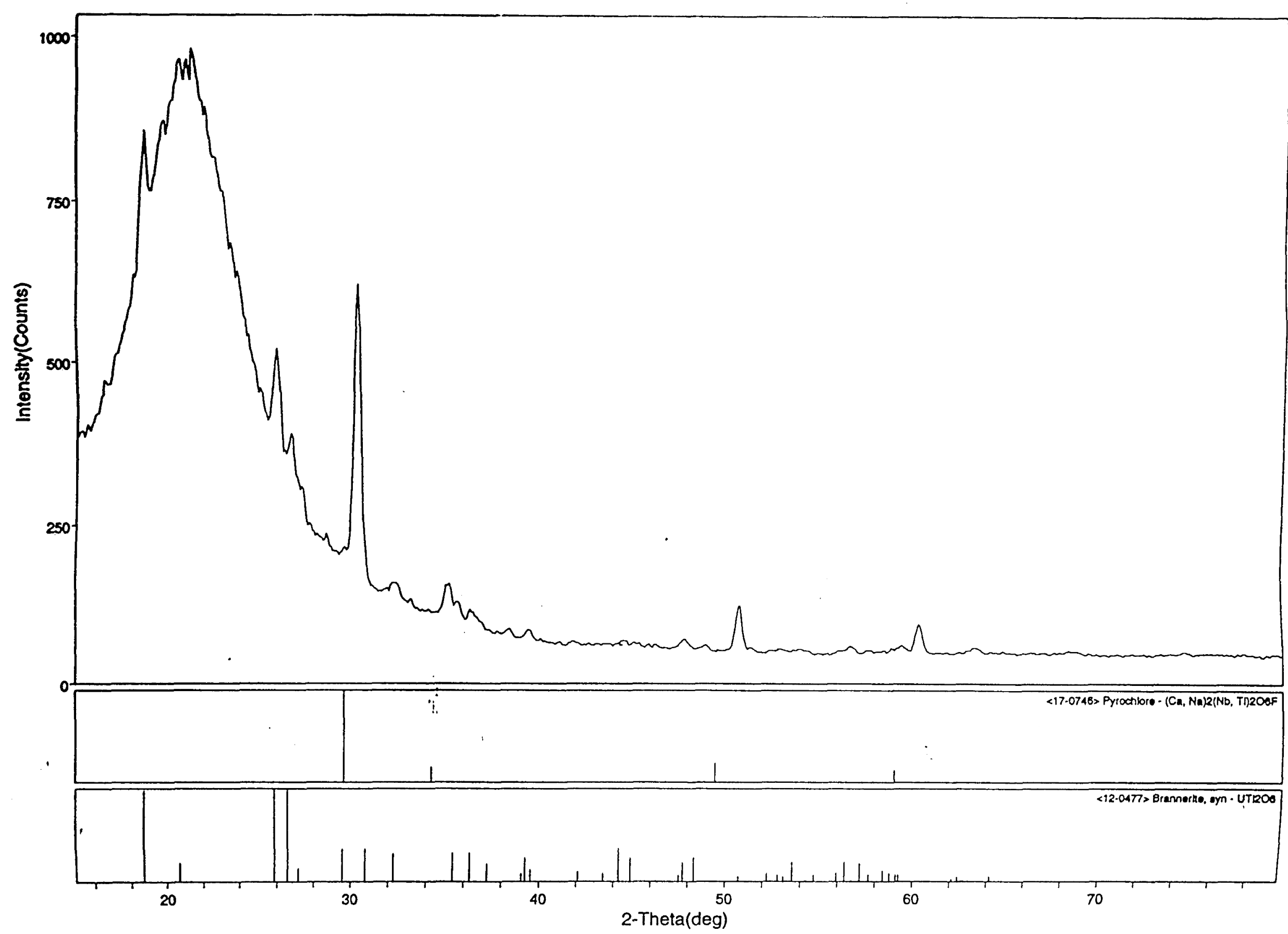




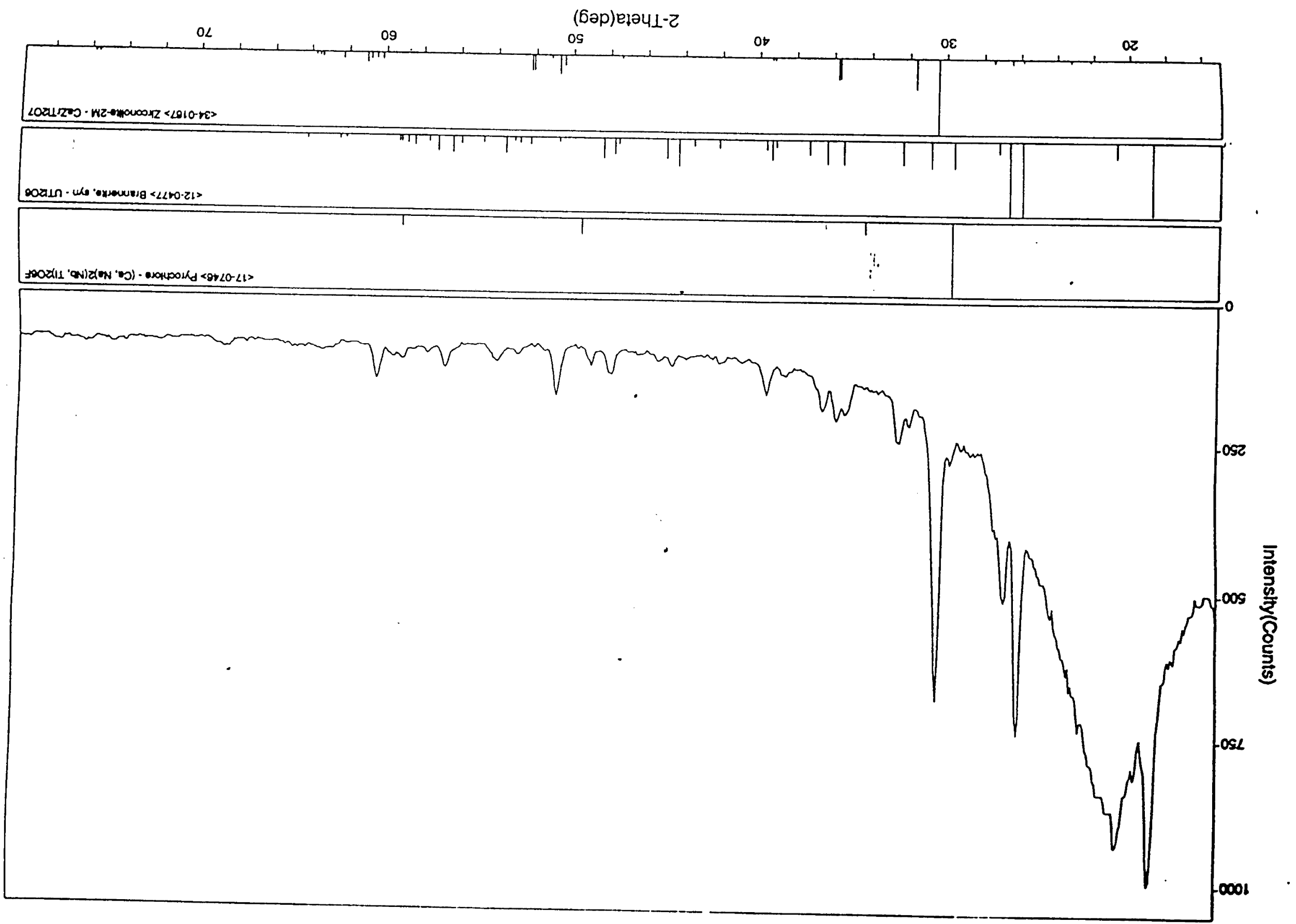

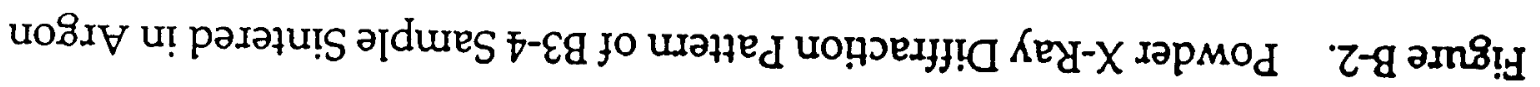




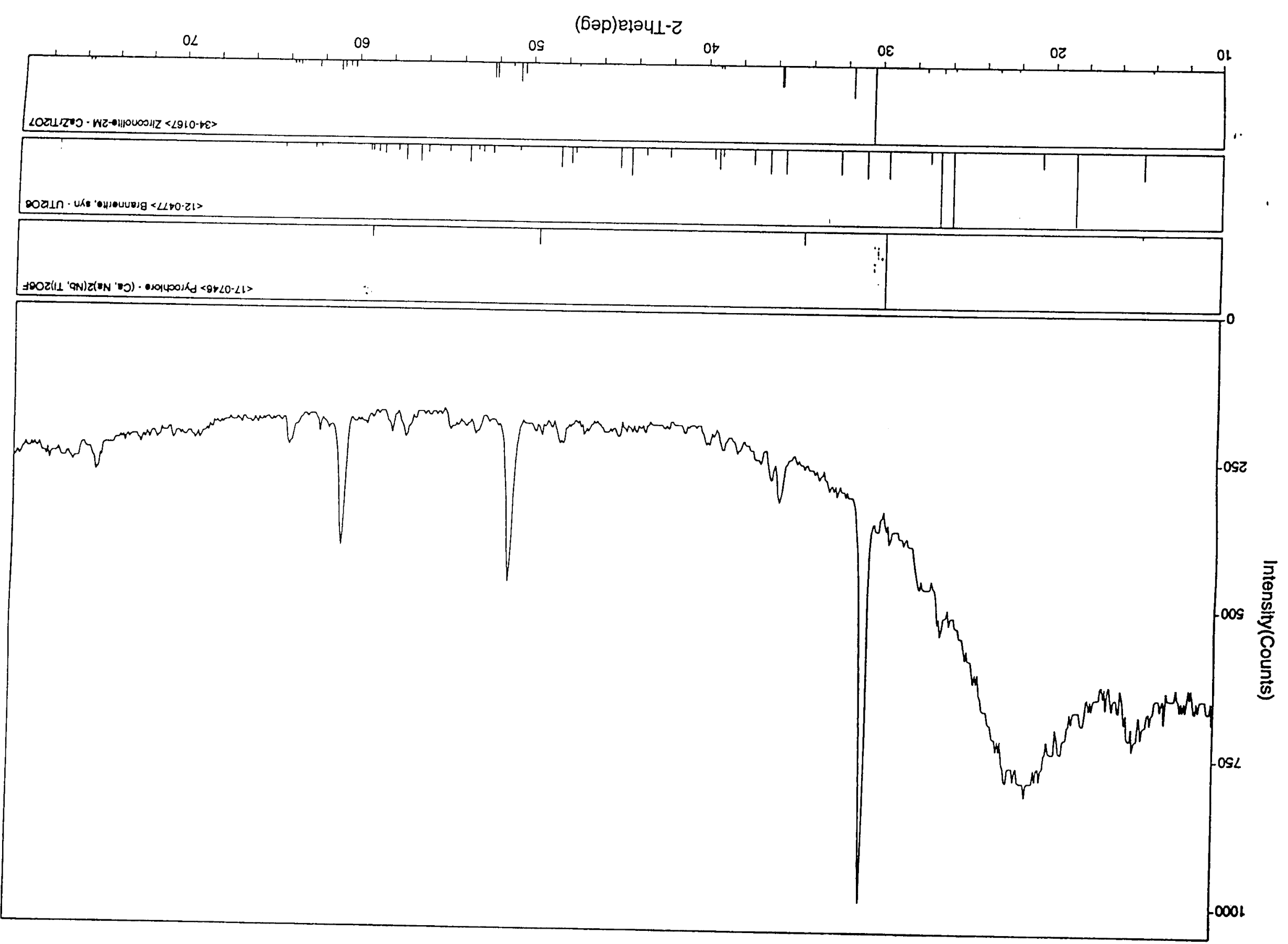




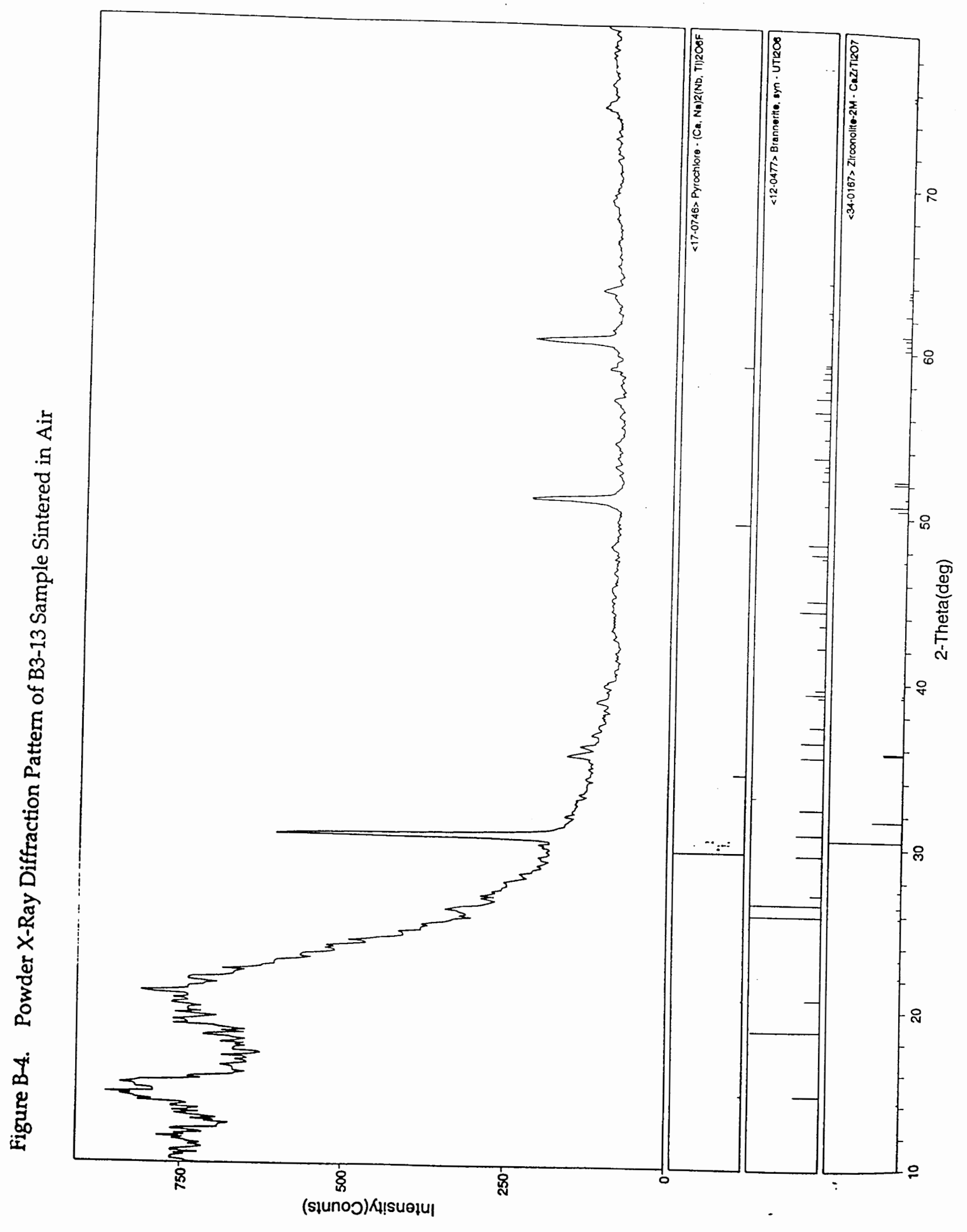




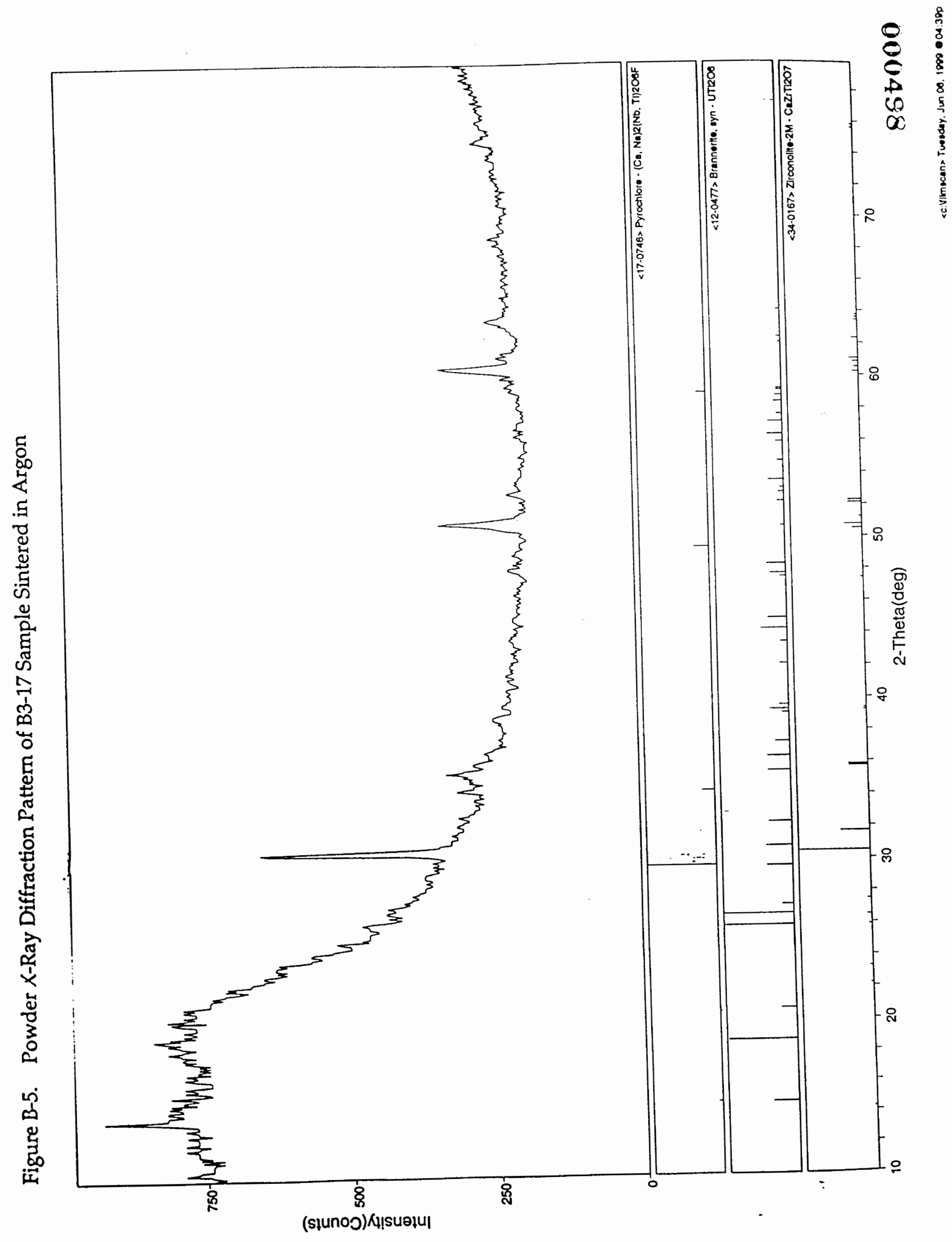




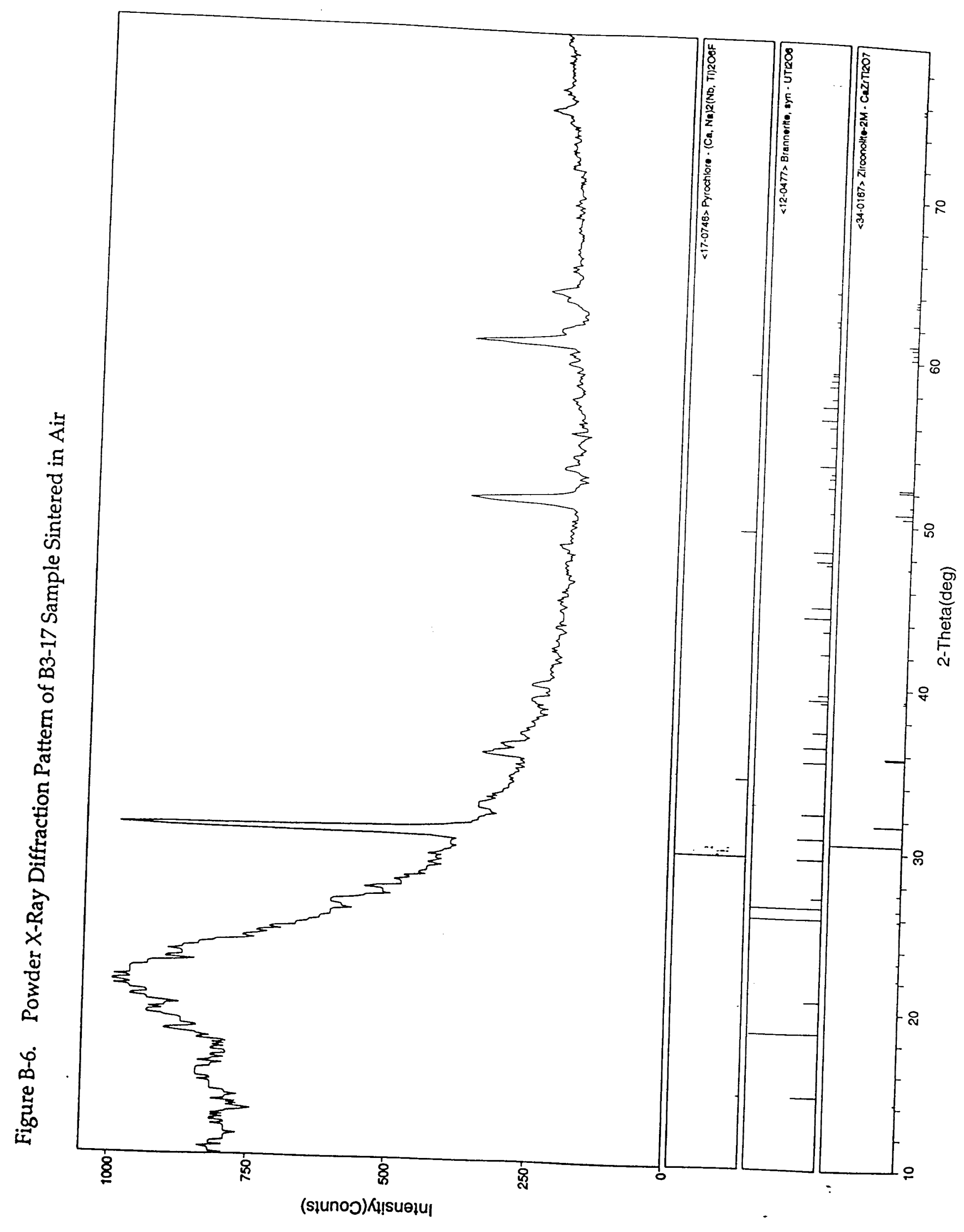


Appendix C. Example Energy Dispersive Spectra 



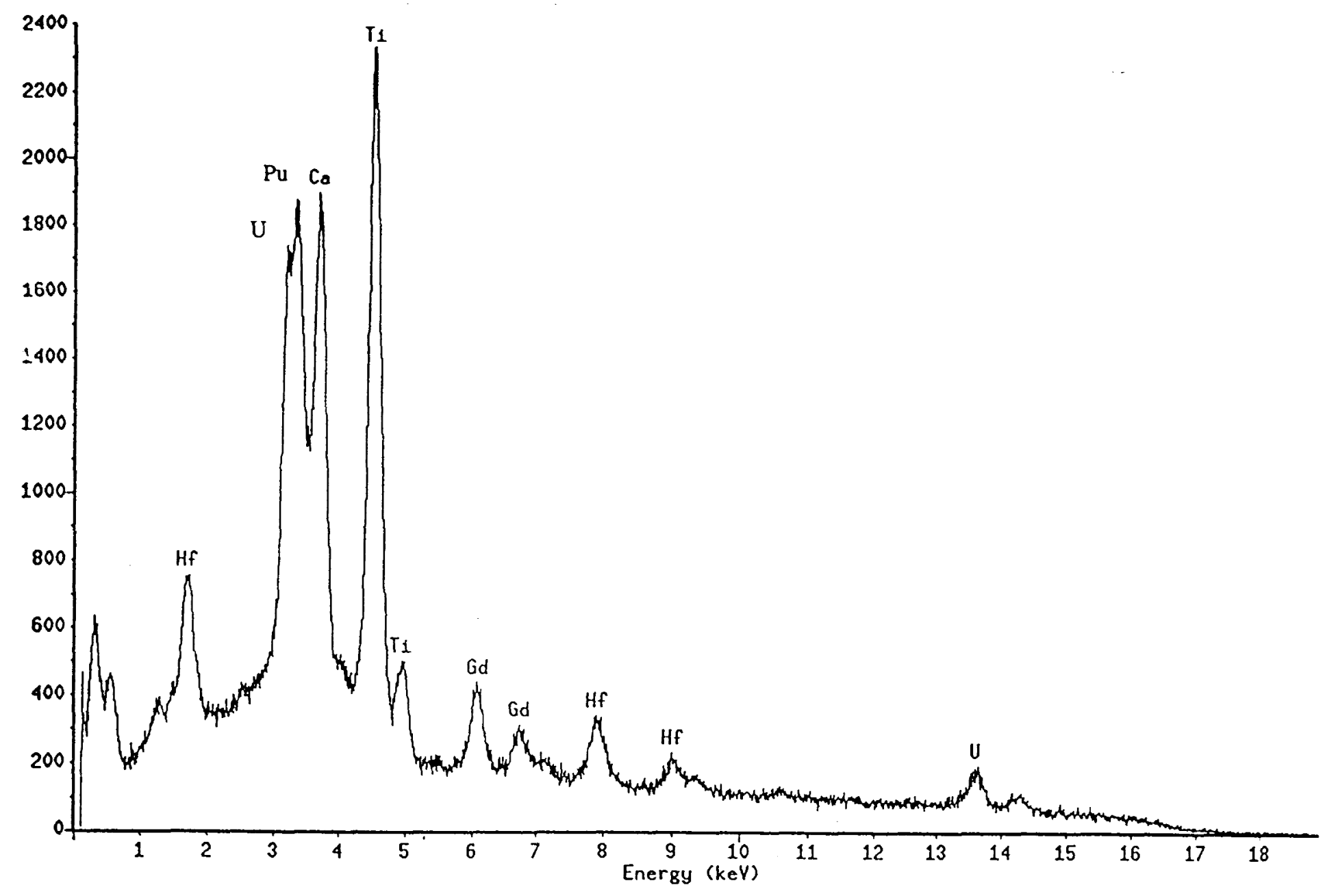

Figure C-1. Typical Energy Dispersive Spectra of Pyrochlore Phase 


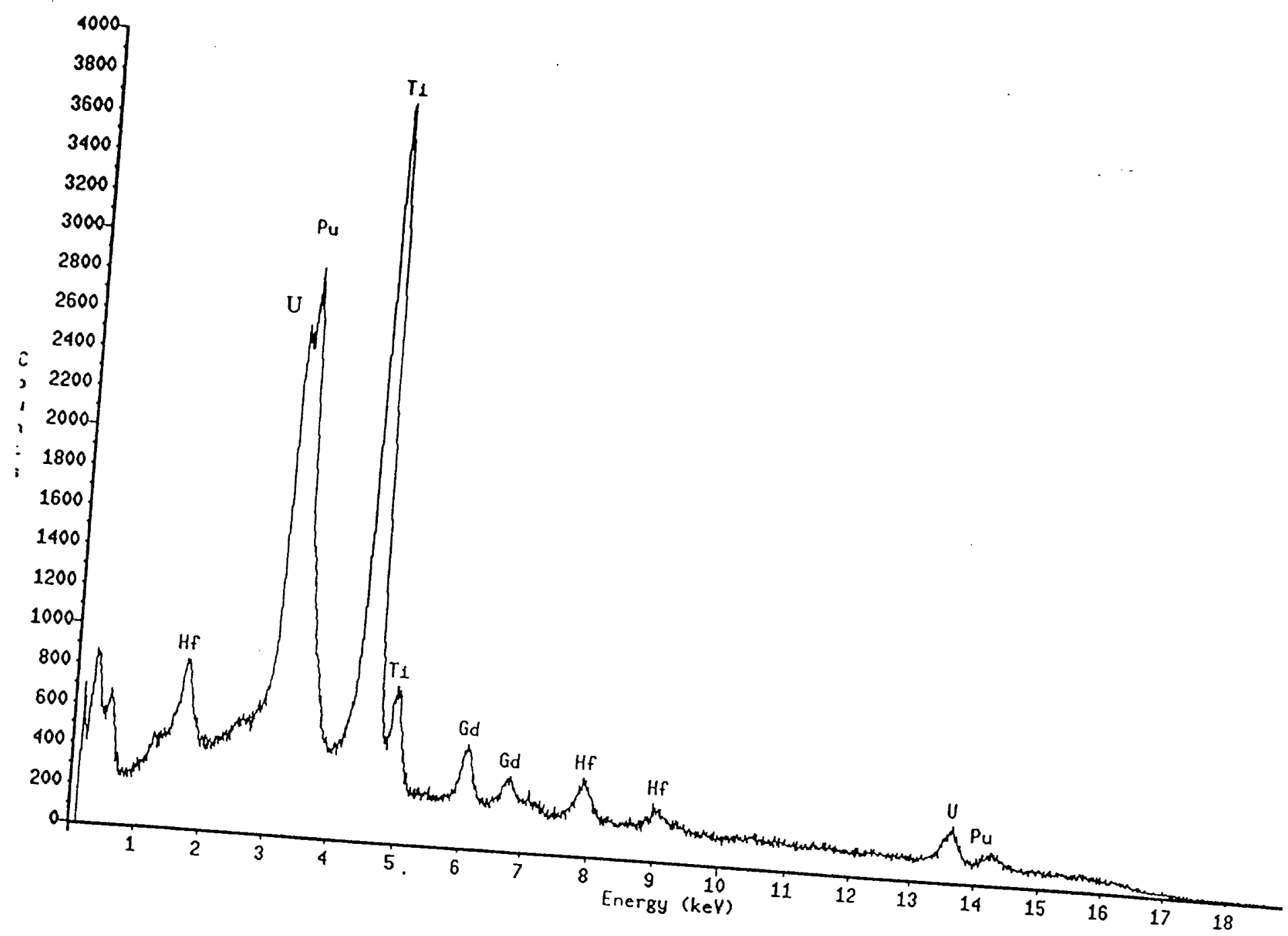

Figure C-2. Typical Energy Dispersive Spectra of Brannerite Phase 


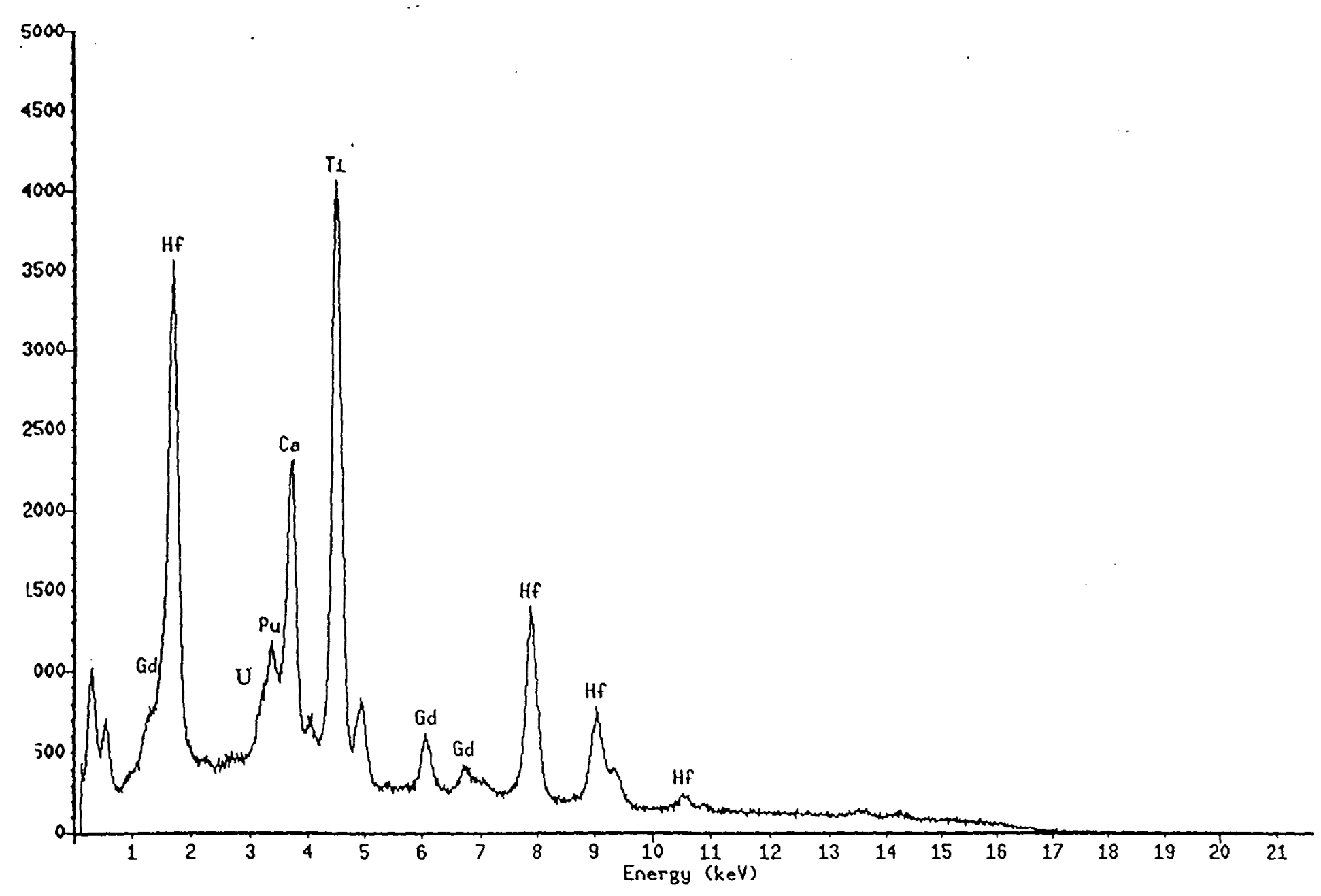

Figure C-3. Typical Energy Dispersive Spectra of Zirconolite Phase 


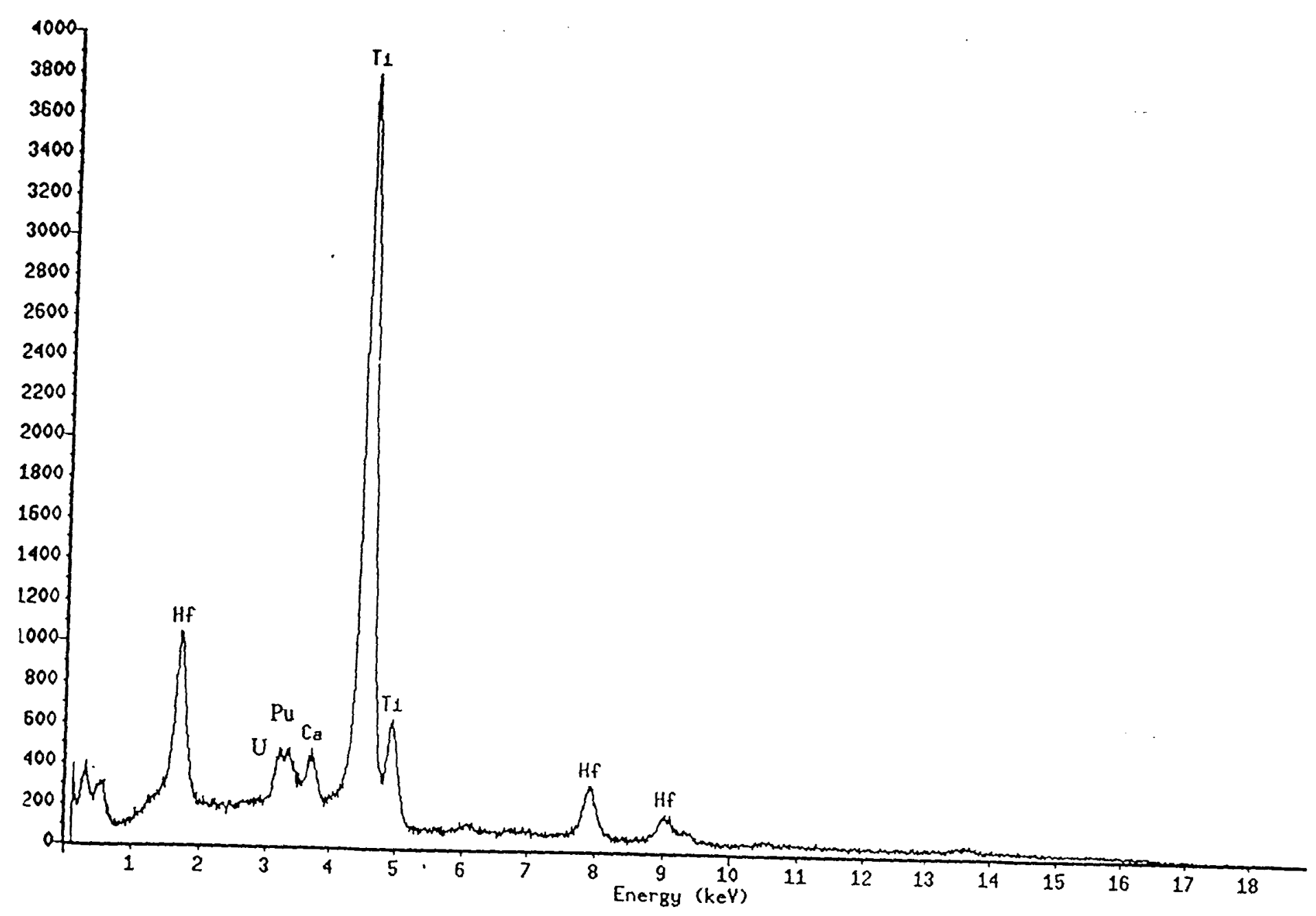

Figure C-4. Typical Energy Dispersive Spectra of Rutile Phase 


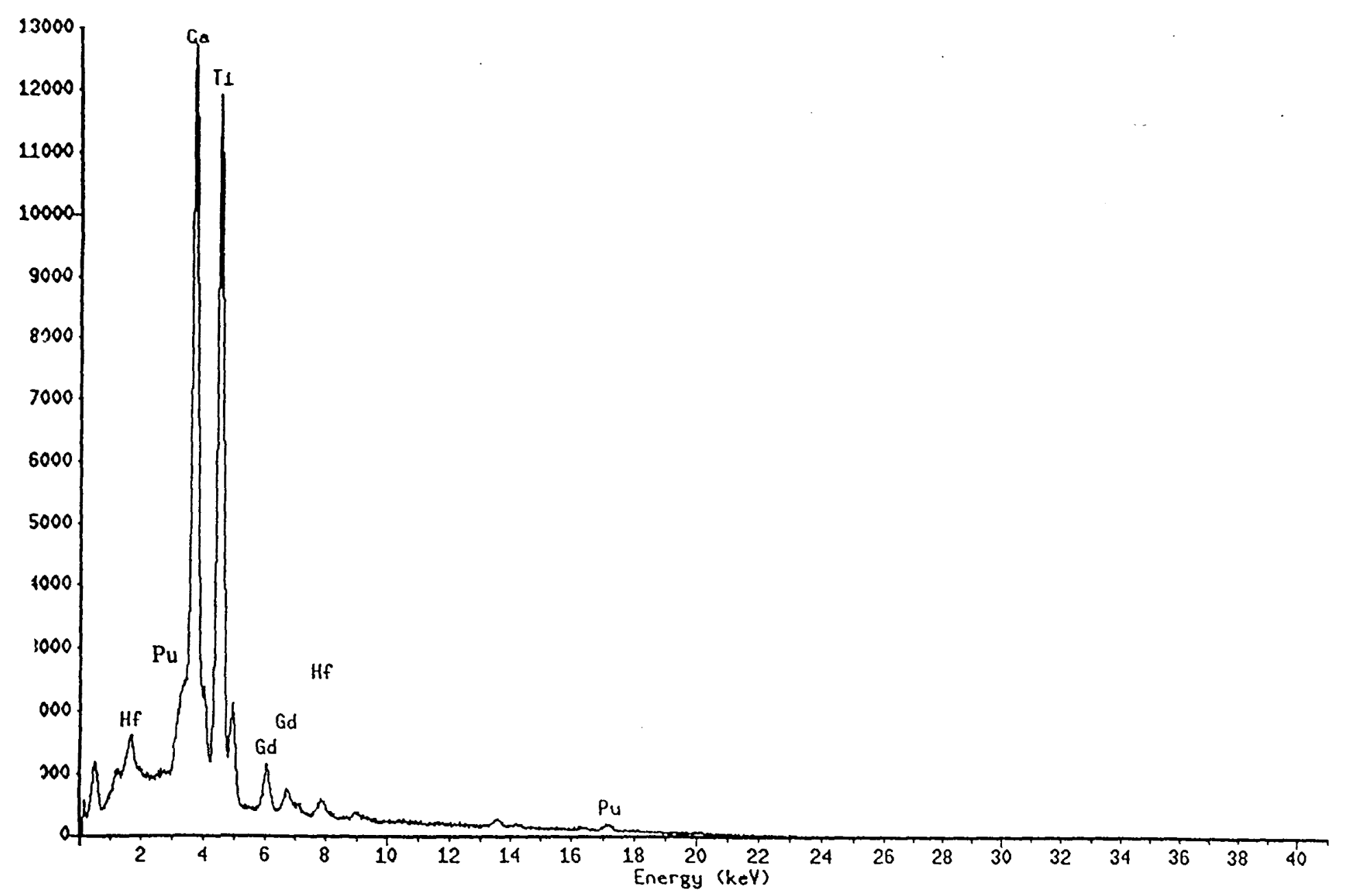

Figure C-5. Typical Energy Dispersive Spectra of Perovskite Phase 


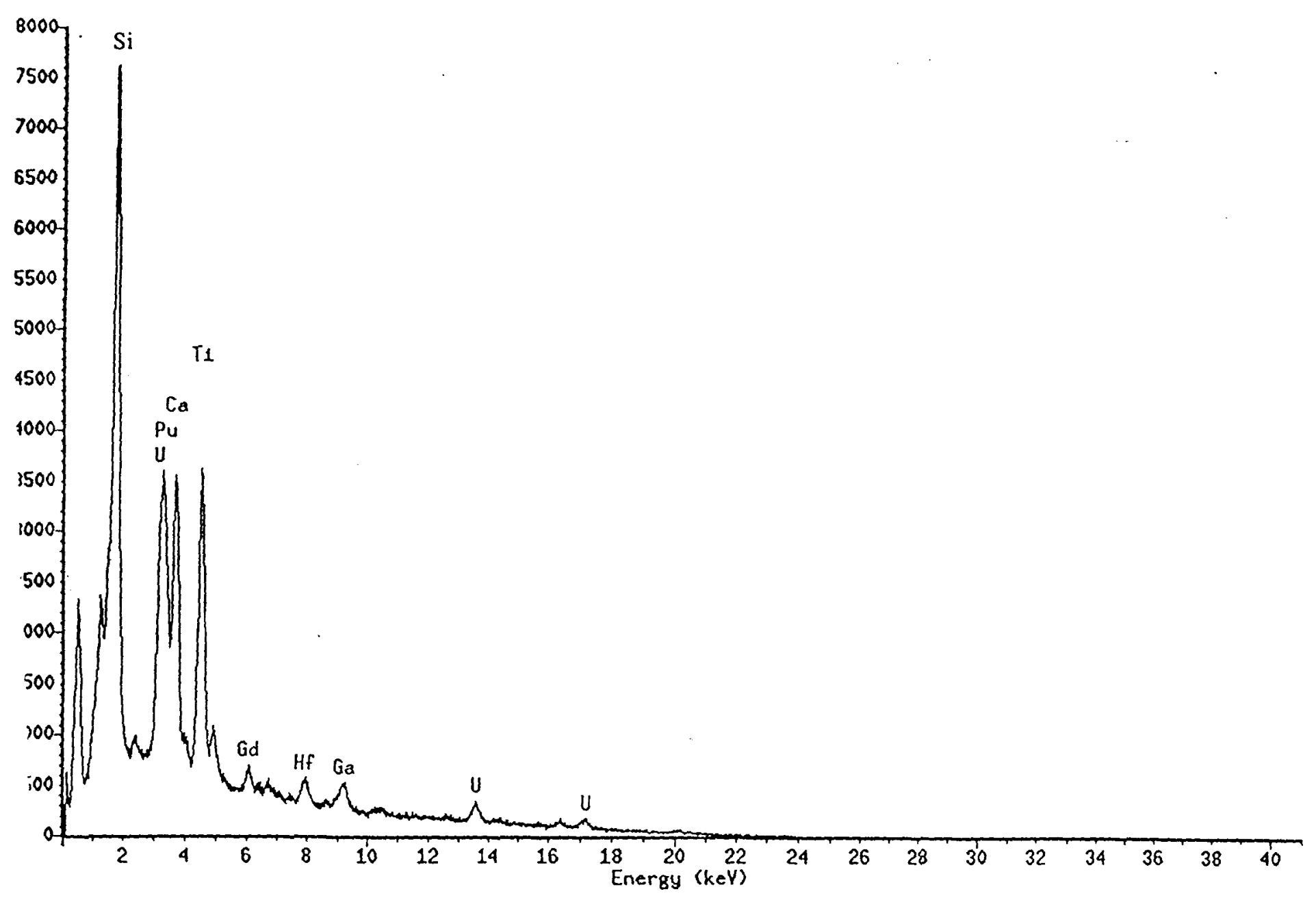

Figure C-6. Typical Energy Dispersive Spectra of Silicate Phase 


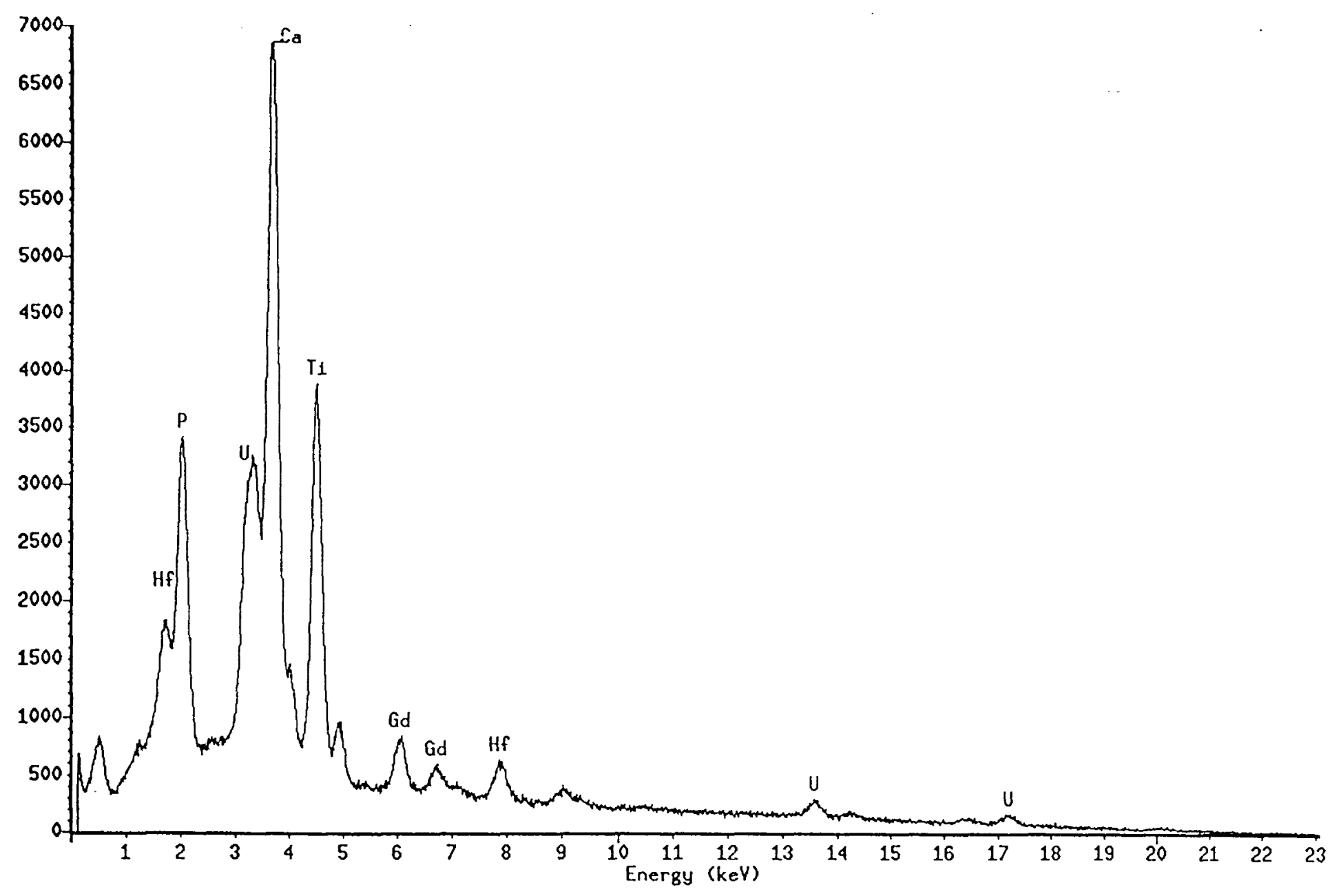

Figure C-7. Typical Energy Dispersive Spectra of Phosphate Phase 


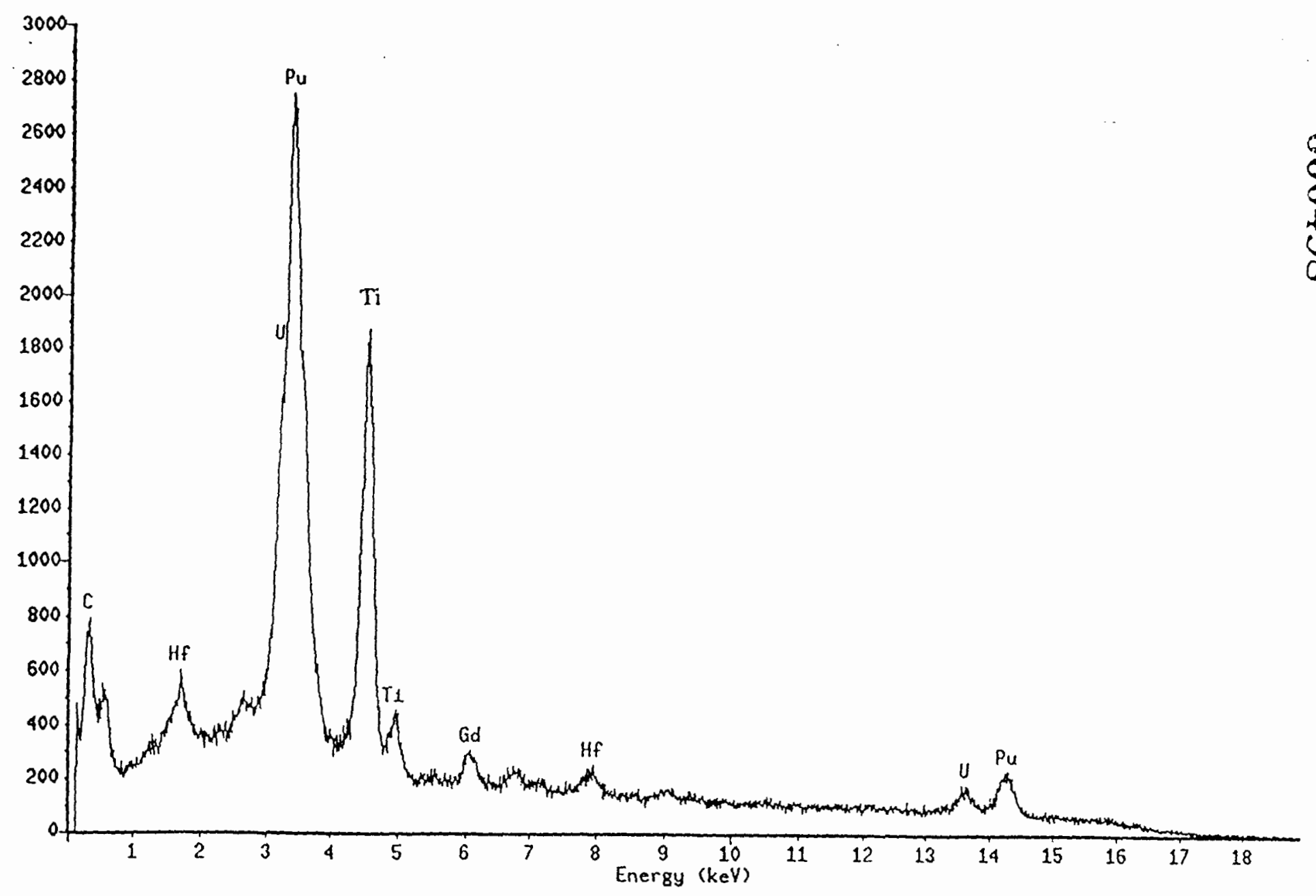

Figure C-8. Typical Energy Dispersive Spectra of Actinide Oxide Phase 
Appendix D. Raw Materials Used in Fabrication of Test Specimens 

Table D-1. Raw Materials Used in Fabrication of Test Specimens

\begin{tabular}{|c|c|c|c|}
\hline Raw Material & $\begin{array}{l}\text { Manufacturer } \\
\text { (product/batch\#) }\end{array}$ & Purity & Maximum Particle Size $(\mu \mathrm{m})$ \\
\hline $\mathrm{TiO}_{2}$ (anatase) & $\begin{array}{l}\text { Fisher } \\
\text { (T315-500/C0067924) }\end{array}$ & $99.9 \%$ & $<44$ \\
\hline $\mathrm{HfO}_{2}$ & $\begin{array}{l}\text { Aldrich } \\
(20,211-8 / 059254 Y)\end{array}$ & $98 \%$ & $<1$ \\
\hline $\mathrm{Ca}(\mathrm{OH})_{2}$ & $\begin{array}{l}\text { Fisher } \\
\text { (C97-500/976282) }\end{array}$ & $99 \%$ & $<44$ \\
\hline $\mathrm{Gd}_{2} \mathrm{O}_{3}$ & $\begin{array}{l}\text { Sigma } \\
\text { (G0125) }\end{array}$ & $99.99 \%$ & $<44$ \\
\hline $\mathrm{UO}_{2}$ & $\begin{array}{l}\text { ANL Stock } \\
\text { (NA) }\end{array}$ & $99 \%$ & 2 \\
\hline $\mathrm{PuO}_{2}$ & $\begin{array}{l}\text { ANL Stock } \\
\text { (NA) }\end{array}$ & $99 \%$ & $a, b$ \\
\hline $\mathrm{CeO}_{2}$ & $\begin{array}{l}\text { Aldrich } \\
(21,157-5 / 05806 \mathrm{BQ})\end{array}$ & $99.9 \%$ & $<5$ \\
\hline $\mathrm{Al}(\mathrm{OH})_{3}$ & $\begin{array}{l}\text { Alfa AESAR } \\
\text { (12366/A26I26) }\end{array}$ & $99 \%$ & $<44$ \\
\hline $\mathrm{H}_{3} \mathrm{BO}_{3}$ & $\begin{array}{l}\text { Alfa AESAR } \\
(10659 / 22417)\end{array}$ & 99.99 & $<44$ \\
\hline $\mathrm{BaO}$ & $\begin{array}{l}\text { General Chemical } \\
(1422 / 13)\end{array}$ & $98 \%$ & $<44$ \\
\hline $\mathrm{CaCl}_{2}$ & $\begin{array}{l}\text { Alfa AESAR } \\
(10680 / 22367)\end{array}$ & $99.99 \%$ & $c$ \\
\hline $\mathrm{Cr}_{2} \mathrm{O}_{3}$ & $\begin{array}{l}\text { Alfa AESAR } \\
(10686 / 22377)\end{array}$ & $99.99 \%$ & a \\
\hline $\mathrm{CuO}$ & $\begin{array}{l}\text { Aldrich } \\
(24,174-1 / 03919 J \mathrm{JF})\end{array}$ & $99 \%$ & $<5$ \\
\hline $\mathrm{CaF}_{2}$ & $\begin{array}{l}\text { Alfa AESAR } \\
\text { (10998/L20E09) }\end{array}$ & $99.93 \%$ & $<44$ \\
\hline $\mathrm{Fe}_{2} \mathrm{O}_{3}$ & $\begin{array}{l}\text { Alfa AESAR } \\
\text { (14680/D23G24) }\end{array}$ & $99.9 \%$ & $<5$ \\
\hline $\mathrm{Ga}_{2} \mathrm{O}_{3}$ & $\begin{array}{l}\text { Alfa AESAR } \\
\text { (10508/RD920518) }\end{array}$ & $99.99 \%$ & $<44$ \\
\hline $\mathrm{K}_{2} \mathrm{CO}_{3}$ & $\begin{array}{l}\text { Fisher } \\
\text { (P208-500/974134A) }\end{array}$ & $99.5 \%$ & $<44$ \\
\hline $\mathrm{La}_{2} \mathrm{O}_{3}$ & $\begin{array}{l}\text { GFS Chemicals } \\
(577 / \text { L609999) }\end{array}$ & $99.99 \%$ & $<44$ \\
\hline $\mathrm{MgO}$ & $\begin{array}{l}\text { Alfa AESAR } \\
(14684 / \mathrm{K} 06 \mathrm{H} 23)\end{array}$ & $99.95 \%$ & $<44$ \\
\hline $\mathrm{MnO}_{2}$ & $\begin{array}{l}\text { Fisher } \\
\text { (M108-500/973987) }\end{array}$ & $99.6 \%$ & $<44$ \\
\hline $\mathrm{M}_{3}$ & $\begin{array}{l}\text { Alfa/AESAR } \\
(36687 / \text { I20G05) }\end{array}$ & $99.99 \%$ & $<44$ \\
\hline $\mathrm{Na}_{2} \mathrm{CO}_{3}$ & Alfa AESAR & $99.5 \%$ & 2 \\
\hline $\mathrm{NiO}$ & $\begin{array}{l}\text { Alfa AESAR } \\
(10819 / 22356)\end{array}$ & $99.99 \%$ & $\begin{array}{l}<44 \\
\cdots:-:\end{array}$ \\
\hline $\mathrm{Nd}_{2} \mathrm{O}_{3}$ & $\begin{array}{l}\text { Alfa AESAR } \\
(11250 / L 10 B 18)\end{array}$ & $99.99 \%$ & $<44$ \\
\hline $\mathrm{P}_{2} \mathrm{O}_{5}$ & $\begin{array}{l}\text { Fisher } \\
\text { (A245-500/974720) }\end{array}$ & $99 \%$ & $<44$ \\
\hline $\mathrm{PbO}$ & J.T. Baker & $99.7 \%$ & $<44$ \\
\hline $\mathrm{SiO}_{2}$ & $\begin{array}{l}\text { Alfa AESAR } \\
(10856 / 22445)\end{array}$ & $99.99 \%$ & $<44$ \\
\hline $\mathrm{SnO}_{2}$ & $\begin{array}{l}\text { Aldrich } \\
(24,465-1 / 00614 \mathrm{LN})\end{array}$ & $99 \%$ & $<44$ \\
\hline $\mathrm{Ta}_{2} \mathrm{O}_{5}$ & $\begin{array}{l}\text { Alfa AESAR } \\
(10881 / 22228)\end{array}$ & $99.99 \%$ & $<44$ \\
\hline $\mathrm{WO}_{3}$ & $\begin{array}{l}\text { Alfa AESAR } \\
(13398 / 22154)\end{array}$ & $99.99 \%$ & $<44$ \\
\hline $\mathrm{ZnO}$ & $\begin{array}{l}\text { ACROS } \\
(315790250 / \text { A0110700001) }\end{array}$ & 99.99 & $<44$ \\
\hline $\mathrm{ZrO}_{2}$ & $\begin{array}{l}\text { ANL Stock } \\
\text { (NA) }\end{array}$ & $99 \%$ & $<44$ \\
\hline
\end{tabular}

- milled in-house to $<10$ microns

- high-fired at $1000^{\circ} \mathrm{C}$ for 2 hours

c- slushy raw material, dissolves readily in water 
